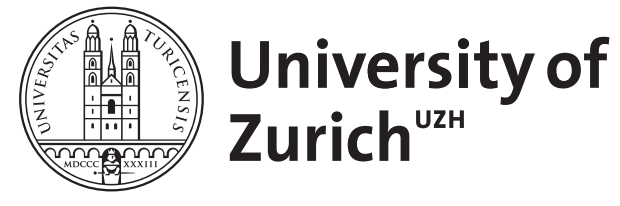

\title{
Muonium chemistry
}

Percival, Paul W

DOI: https://doi.org/10.1524/ract.1979.26.1.1

Posted at the Zurich Open Repository and Archive, University of Zurich ZORA URL: https://doi.org/10.5167/uzh-153928

Journal Article

Published Version

Originally published at:

Percival, Paul W (1979). Muonium chemistry. Radiochimica Acta: international journal for chemical aspects of nuclear science and technology, 26(1):1-14.

DOI: https://doi.org/10.1524/ract.1979.26.1.1 


\section{Muonium Chemistry}

\section{By Paul W. Percival, Physikalisch-Chemisches Institut der Universität Zürich, Winterthurerstr. 190 CH-8057 Zürich}

(Received October 27, 1978; revised November 29, 1978)

Hydrogen isotopes / Isotope effects / Muonium / $\mu S R$ /Radiolysis / addition, e. g. Review

$$
\mathrm{Mu}+\mathrm{R}_{2} \mathrm{C}=\mathrm{CH}_{2} \rightarrow \mathrm{R}_{2} \dot{\mathrm{C}} \mathrm{CH}_{2} \mathrm{Mu},
$$

\section{Summary}

Muonium is a single-electron hydrogen-like atom with a shortlived elementary particle, the positive muon $\left(\mu^{+}, \mathrm{m}_{\mu}=\frac{1}{9} \mathrm{~m}_{\mathrm{p}}\right.$, $\tau=2.2 \times 10^{-6} \mathrm{~s}$ ) as nucleus. It is formed by stopping high energy $\mu^{+}$in matter. Spin polarized muons in a magnetic field give rise to precession signals characteristic of their chemical environment. Three types of species are identifiable by the $\mu^{+}$SR technique: (i) Bare muons, or muons substituted in diamagnetic molecules (in place of protons); (ii) Free muonium; and (iii) Muonium substituted free radicals. Observation of these signals is restricted to times $\gtrsim 10^{-7} \mathrm{~s}$, but their initial amplitudes also contain information about processes occurring between $10^{-11} \mathrm{~s}$ and $10^{-8} \mathrm{~s}$. Muonium can be detected in various inert gases and in water, methanol and ethanol. Rates of reaction have been determined directly from the observed signal decay. Comparison of rate constants for muonium reactions with the corresponding hydrogen atom data reveals kinetic isotope effects of varying degree. Such results provide valuable material for tests of reaction rate theories. Isotope effects of the structural kind are found for the isotopic muon-electron hyperfine coupling constants measured for the free radicals formed when muonium adds to an unsaturated molecule. The results have been interpreted in terms of the relative occurrence of different radical conformers. The nature of the "early events" in muonium chemistry, which determine the distribution of muons between the various types of muonic species, is a matter of some dispute. Recent evidence from aqueous systems suggests that muonium is formed in the terminal spur of the muon track. This contrasts with the older view that muonium is formed at epithermal energies by electron abstraction from the medium, and that the initial diamagnetic fraction constitutes the products of hot muonium reactions.

\section{Introduction}

Muonium is the exotic atom consisting of a positive muon $\left(\mu^{+}\right)$and an electron. The positive muon is an elementary particle, a lepton; some important properties are listed in table 1 . It is of general interest to the particle physicist $[1,2]$ and finds wide applicability in solid-state physics [3], but its chemical significance $[4,5]$ is solely due to its role as the nucleus of the single electron hydrogen-like muonium atom. Although the muon has only $1 / 9$ the rest mass of the proton the reduced mass of muonium is within $0.5 \%$ that of $\mathrm{H}$, so that the atomic Bohr radius and ionization potential are correspondingly close to those of $\mathrm{H}$ (see table 1). From a chemical point of view, then, muonium is a light isotope of hydrogen, and may be expected to undergo analogous reactions [6]:

abstraction (of $\mathrm{H}, \mathrm{Br}$ )

$$
\mathrm{Mu}+\mathrm{RX} \rightarrow \mathrm{MuX}+\mathrm{R} \cdot
$$

radical combination, e. $g$.

$$
\mathrm{Mu}+\cdot \mathrm{OH} \rightarrow \mathrm{MuOH},
$$

electron transfer

$$
\mathrm{Mu}+\mathrm{M}^{n^{+}} \rightarrow \mu^{+}+\mathrm{M}^{(n-1)^{+}}
$$

and

$$
\mathrm{Mu}+\mathrm{OH}^{-} \rightarrow \mathrm{MuOH}+\mathrm{e}_{\mathrm{aq}}^{-}
$$

If $\mathrm{Mu}$ were to react exactly like $\mathrm{H}$, it would of course be uninteresting. However mass differences can influence rates of reaction - the kinetic isotope effect. The large number of factors which influence reactions rates makes it essentially impossible to predict absolute rate constants with any degree of precision. Therefore, tests of reaction rate theories rely to a great extent on the comparison of predicted and experimental kinetic isotope effects. This is particularly so [7] for those empirical computations where parameters are adjusted to give the best fit to experimental results. The inclusion of muonium in the series of hydrogen isotopes (mass ratios $3: 2: 1: 0.11$ ) vastly increases the scope of such studies. Furthermore the lightness of muonium provides a means to investigate the contribution of tunnelling in chemical reactions, otherwise more or less experimentally unattainable.

Structural isotope effects may also be studied by means of muonium. Addition reactions, such as eq. (2), lead to muonic radicals whose hydrogen counterparts are often well-known [cf. $\left(\mathrm{CH}_{3}\right)_{2} \mathrm{CCH}_{2} \mathrm{Mu}$ and t-butyl]. Comparison of hyperfine coupling constants, in particular their temperature dependencies, leads to information about molecular configurations.

Table 1. Muon and muonium properties

\begin{tabular}{rrl}
\hline Muon $\quad$ (positive) & $\boldsymbol{\mu}^{+}$ \\
spin & $1 / 2$ \\
mass & $1 / 9$ mass of proton \\
magnetic moment & 3.18 proton magnetic moment \\
lifetime & $2.20 \mu \mathrm{s}$ \\
& \\
Muonium, Mu & $\mu^{+} \mathrm{e}^{-}$ \\
mass & $1 / 9$ mass of $\mathrm{H}$ \\
Bohr radius & $0.532 \AA$ \\
ionization potential & $13.539 \mathrm{eV}$ \\
lifetime & limited by that of $\mu^{+}$
\end{tabular}


Applications of muonium are by no means restricted to studies of isotope effects, however. As explained in the following Section, the muon is born with a high degree of spin polarization, and is monitored by a single particle counting technique. It is thus an ideal tracer, being employed in the limit of infinite dilution. Due to the high sensitivity of the method typically $10^{6}-10^{7}$ good events suffice in an experiment, corresponding to irradiation of the sample (a few $\mathrm{cm}^{3}$ volume) with $10^{8}-10^{9} \mu^{+}$. Damage is therefore kept to a minimum. The short lifetime of the muon, $2.2 \times 10^{-6} \mathrm{~s}$ (independent of chemical environment), limits study to fast processes, but it is just the se that are difficult to investigate by other means.

As a further consequence of its production the muon enters the chemical target with high energy (MeV). Its early lifetime is therefore inextricably bound up with physicochemical processes of radiation chemistry nature. The extent of hot atom reactions $[8,9]$ is still an open question.

\section{Experimental considerations}

\subsection{Muon production and decay}

The decay of pions is utilized to produce muons in sufficient number for practical purposes. The pions are themselves products of nuclear reactions initiated by high energy protons $(400-800 \mathrm{MeV})$. Muonium chemistry experiments are therefore restricted to the few sites in the world which have suitable particle accelerators. The proton synchrotrons at CERN, Dubna and Lawrence Berkeley Laboratory have been used, and also some smaller establishments. In recent years, however, the demand for high intensity beams of pions and muons has led to the creation of three "meson factories": LAMPF (Los Alamos Meson Physics Facility), SIN (Swiss Institute for Nuclear Research) and TRIUMF (Tri-University Meson Facility, at Vancouver).

The pion decays to give a muon and a neutrino:

$$
\pi^{+} \rightarrow \mu^{+}+\nu_{\mu}
$$

Since spin and momentum must be conserved in this reaction, and the neutrino has negative helicity, it follows that the spin of the muon is anti-parallel to its momentum (in pion centre-of-mass coordinates). Thus judicious momentum selection of muons from the in-flight decay of pions results in a muon beam of high spin polarization ( $~ 80 \%)$, and momentum typically in the range 50-125 $\mathrm{MeV} / \mathrm{c}$. Alternatively a low energy "Arizona" beam can be obtained from pions which decay at rest; the resulting muons are essentially monochromatic $(29.8 \mathrm{MeV} / \mathrm{c})$. In either case the muons are degraded and stopped in the target of interest.

Whilst in the sample the muon decays, emitting a positron and two neutrinos:

$$
\mu^{+} \rightarrow \mathrm{e}^{+}+\bar{\nu}_{\mu}+\nu_{\mathrm{e}}
$$

The angular distribution of positrons is anisotropic; the $\mathrm{e}^{+}$emission probability is proportional to $1+a \cos \theta$, where $\theta$ is the angle between the muon spin and positron momentum directions. The asymmetry coefficient $a$ is a function of positron energy, and takes an average value of about 0.3 . As a result the variation of positron detection probability in a given direction reflects the evolution of muon spin polarization.

\section{2. $\mu$ SR: Muon spin rotation}

The transverse field $\mu \mathrm{SR}$ technique is by far the most common experimental method used in the study of muonium chemistry; nowadays it is almost exclusive. A magnetic field perpendicular to the initial muon spin direction is applied to the sample. One or more precession signals ensue, according to the number and type of muonic species created by the stopped muons. Plastic scintillator counters are grouped (in "telescopes") about the sample to detect the passage of individual muons and positrons.

The experimental set-up is shown schematically in Fig. 1. To stop in the sample a muon must pass through counters $a$ and $b$ but not $c$. Thus the muon stop signature is $a \cdot b \cdot \bar{c}$. Correspondingly $\bar{b} \cdot c \cdot d$ represents $\mathrm{e}^{+}$emission in the forward (muon beam) direction. The two signatures form the start and stop signals for a lifetime counting apparatus consisting of a time-to-amplitude converter, multichannel analyzer, and associated logic units which serve to reject imperfect events. Only unequivocal single $\mu^{+}$stop / correlated $\mathrm{e}^{+}$emission events are retained.

In the absence of a magnetic field the histogram accumulated in the multichannel analyzer would depict a single exponential with decay time $2.2 \times 10^{-6} \mathrm{~s}$, the muon lifetime. Precession of the muon spin in a magnetic field results in oscillation of the $\mathrm{e}^{+}$detection probability in the forward telescope, and gives rise to the wiggles shown in

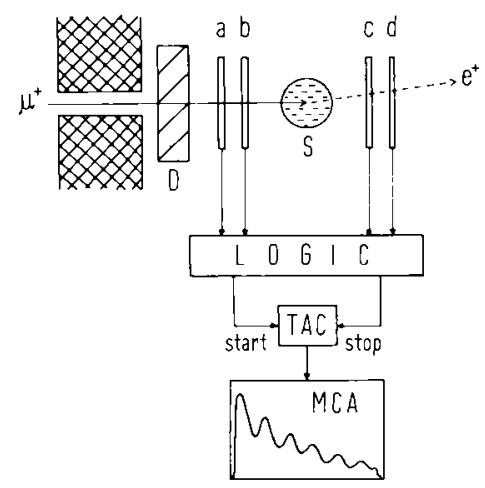

Fig. 1. Schematic representation of a $\mu$ SR experimental assembly. Individual muons pass through the collimator, slow down in the degrader $(D)$ and stop in the sample $(S)$, where they decay. Scintillator counters $(a, b, c$ and $d)$ detect the passage of the muon and also the decay positron if it is emitted in a suitable direction. The muon lifetime is registered by the time-to-amplitude converter $(T A C)$ and a frequency histogram is accumulated in the multichannel analyzer $(M C A)$ 


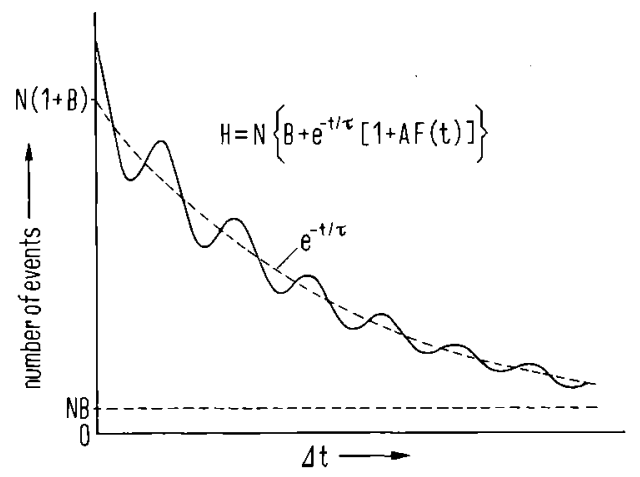

Fig. 2. Schematic representation of a $\mu$ SR histogram. The ordinate denotes the number of muons which decay to emit their positrons in a particular direction. $\Delta t$ is the ind ividual muon lifetime

Fig. 2. The general form of the histogram is

$$
H=N\left\{B+\mathrm{e}^{-\mathrm{t} / \tau}[1+A F(t)]\right\},
$$

where $N$ is the normalization factor, $B$ the background and $\tau$ the muon lifetime. $F(t)$ is the normalized timedependence of the muon spin polarization. The asymmetry constant $A$ (typically 0.2 ) includes the initial beam polarization, the coefficient $a$, and various geometrical factors. These pieces of information are uninteresting, and so it is usual to calibrate the experimental assembly with a standard sample and quote the signal amplitudes in terms of muon polarization fractions $P_{i}$ (Section 8.1).

Three different classes of muonic species are identifiable on the basis of their characteristic precession signals $F(t)$. They are dealt with in the following Section.

\section{Muon precession signals}

\subsection{The diamagnetic signal}

The spins of bare muons, or muons substituted in diamagnetic molecules (e. g. MuOH) precess at their nuclear Larmor frequency, $13.55 \mathrm{kHz} / \mathrm{G}$. An example of this diamagnetic signal is shown in Fig. 3, together with the $\mu \mathrm{SR}$ histogram from which it was extracted by removal of background and exponential decay. The resolution of conventional $\mu \mathrm{SR}$ apparatus is such that the small chemical shifts typical of proton $\mathrm{nmr}$ are not discernable. The diamagnetic $\mu \mathrm{SR}$ signal is thus analogous to a very low resolution proton magnetic resonance signal, or more precisely, to the free induction signal induced by the $\pi / 2$ pulse in Fourier transform $\mathrm{nmr}$.

Almost all substances so far investigated give rise to the diamagnetic signal. Its amplitude in water, simple alcohols and many other saturated organic compounds corresponds to about $60 \%$ of the original muon polarization.

\subsection{Muonium}

Muonium is a two-spin system, and its precession signal is correspondingly more complicated than that of the single muon (see Fig. 4). In the absence of a magnetic field the
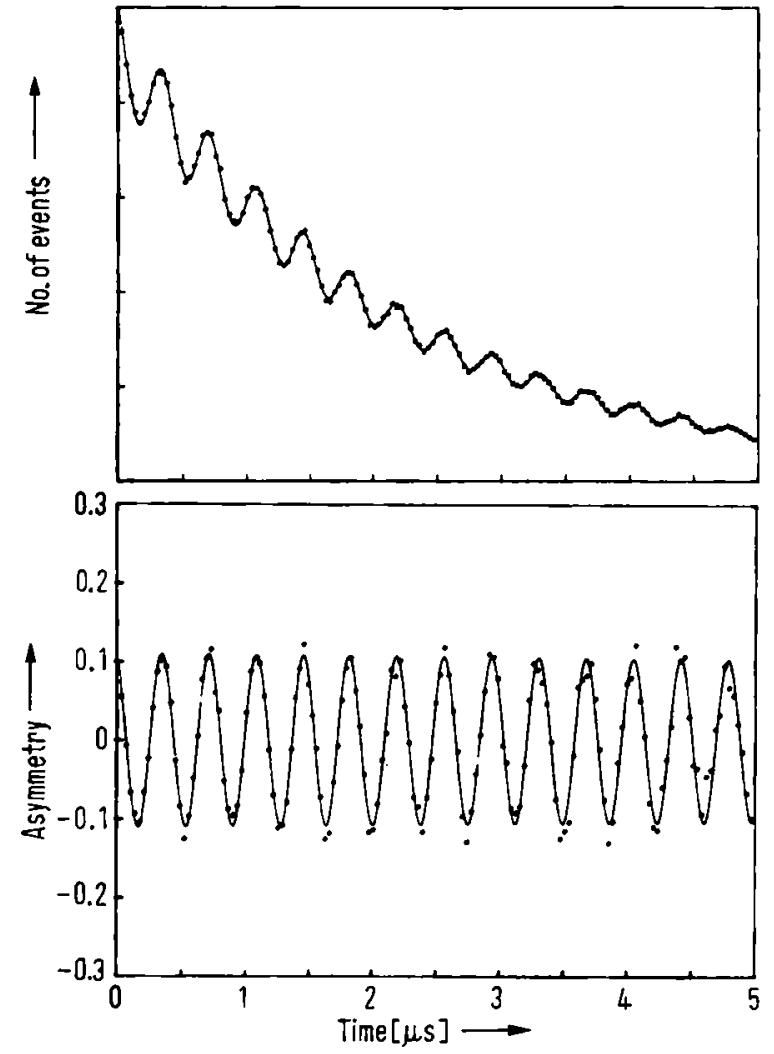

Fig. 3. $\mu$ SR histogram (upper) and diamagnetic signal (lower) from water in a transverse magnetic field of $200 \mathrm{G}$. The precession signal, $A F(t)$ is obtained from the histogram by subtraction of

the background and removal of the exponential muon decay

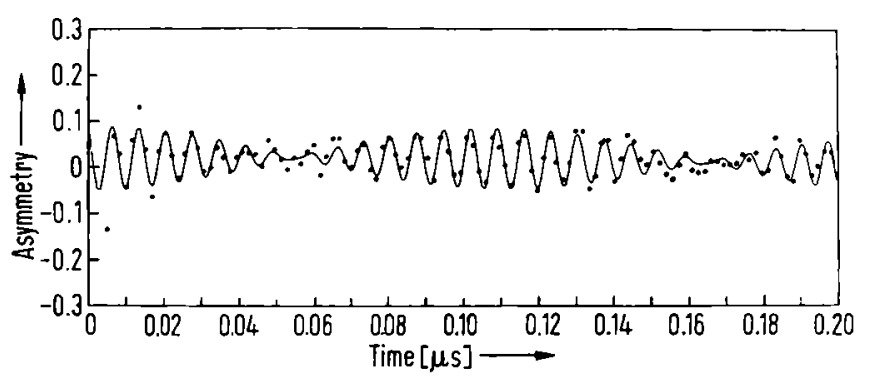

Fig. 4. Muonium precession signal from quartz in $101 \mathrm{G}$ field

spins combine to give a singlet and a triplet. The degeneracy of the triplet is lifted in a magnetic field; the variation of the four energy levels as a function of field strength is given by the well-known Breit-Rabi diagram (Fig. 5). The dimensionless field parameter $x$ is given by the ratio: (sum of electron and muon Larmor frequencies) / (muonelectron hyperfine frequency, $\omega_{0}$ ). For fields transverse to the muon spin polarization, four transitions are allowed, giving rise to four characteristic frequencies. Of these, two, denoted by dotted lines in Fig. 5, are too high to be resolved by conventional $\mu \mathrm{SR}$ apparatus. The remaining two, depicted by the full lines, give rise to the beat pattern shown in Fig. 4. At very low fields the two observable frequencies become degenerate, as demonstrated by the Fourier transform spectrum [of $A F(t)$ ] for water at $10 \mathrm{G}$ (Fig. 6a). This "muonium precession" signal arises from the precession of the triplet coupled $\left(M_{F}=1\right)$ muon- 


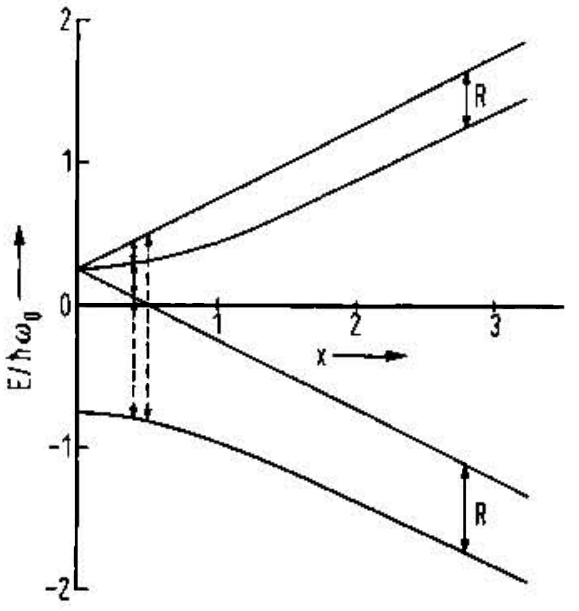

Fig. 5. Breit-Rabi diagram showing the energy levels of a TwoSpin $1 / 2$ System as a function of magnetic field. The diamagnetic field parameter $x$ represents the ratio of Larmor to hyperfine frequencies. Of the four transition frequencies allowed in low transverse fields, only the two denoted by full lines are resolvable. The transitions marked $R$ are those detected for muonic radicals in high fields

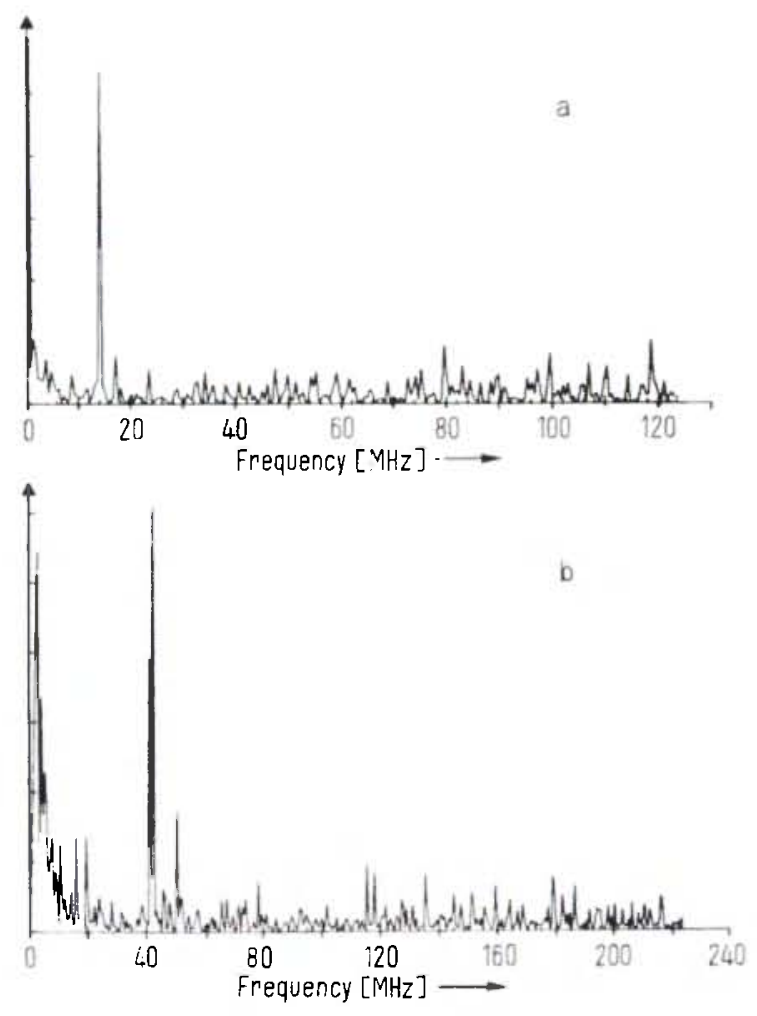

Fig. 6. Fourier transforms of the muonium precession signals from water in $a$ ) $10 \mathrm{G}$, and b) $30 \mathrm{G}$ transverse fields

electron spin vector about the magnetic field, and takes the value $1.4 \mathrm{MHz} / \mathrm{G}$ (roughly half the electron Larmor frequency). In higher fields the splitting becomes apparent (Fig. 6b); the magnitude of the splitting and the amplitudes of the individual frequencies are functions of $x$, i. e. they depend on the magnetic field strength and the hyperfine coupling constant.

Muonium has been clearly identified in gaseous argon, krypton, xenon and nitrogen [10-14]; in quartz, solid $\mathrm{CO}_{2}$ and ice $[15,16]$; and in liquid water, ethanol and methanol [17, 18]. Muonium-type signals have also been detected in the semiconductors silicon and germanium $[16,19]$, where further "anomalous muonium" (radicaltype) signals have also been discovered [19-21].

\subsection{Free radicals}

A free radical (electron spin doublet) containing a muon but no other magnetic nucleus would exhibit Breit-Rabi splitting similar to muonium, but modified to account for the smaller muon-electron hyperfine interaction. Of the four precession frequencies, two gain in amplitude with increasing magnetic field and two fall; in the highfield limit only two remain (designated $R$ in Fig. 5).

Now, typical organic free radicals contain many magnetic nuclei, in particular protons, so that in general their $\mu \mathrm{SR}$ spectra are much more complicated than that of muonium. Indeed the multiplicity of frequencies can lead to a smearing out of the signal, so that detection becomes impossible. Nevertheless, in high fields, where the electron Larmor frequency exceeds the muon hyperfine frequency, the spectrum simplifies to the two frequencies found for the muonium case. The situation is akin to the ENDOR of free radicals in solution, where each proton gives rise to a pair of lines split symmetrically about the Larmor precession frequency [22]. The magnitude of the splitting

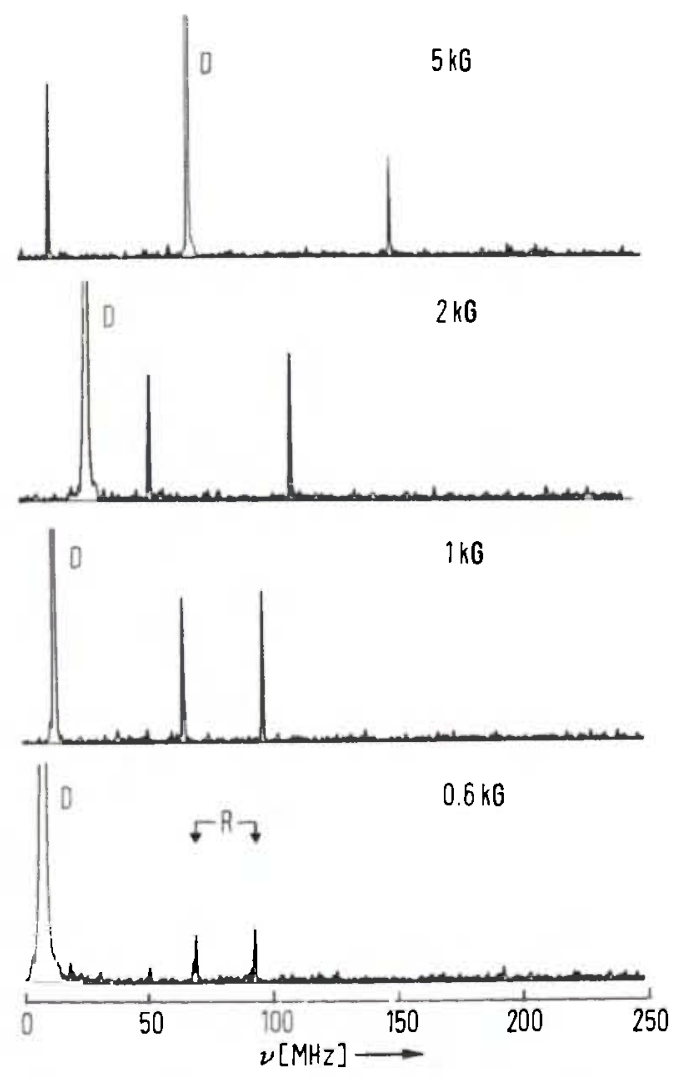

Fig. 7. Fourier transforms of the precession signals from 2,3-dimethyl-2-butene at various magnetic fields. The diamagnetic signal is denoted by $D$, and the pair of radical frequencies by $R$. Not apparent from these Fourier power spectra is that the lower radical frequency is in reality negative 
equals the hyperfine coupling constant. Fourier transform $\mu$ SR spectra obtained from 2,3-dimethyl-2-butene at different magnetic fields are shown in Fig. 7. Given that the lower of the two radical frequencies $(R)$ is in reality negative, it can be seen that they are indeed symmetrically placed about the diamagnetic signal $(D)$.

\subsection{Transformations between muonic species}

When one muonic species is transformed into another with different precession frequencies some or all of the muon spin polarization may be lost. This frequently occurs in the reactions of muonium. Polarization is conserved only if the reaction rate is large compared with the difference between the initial and final precession frequencies. This can be readily understood as follows: In a slow reaction the lifetimes of individual reactant species are distributed over all or part of a precession period, so that muon spins in the reaction product become dephased. Although no individual spins are lost, the ensemble polarization as exhibited by the $\mu$ SR histogram is reduced. The same process leads to line broadening in magnetic resonance. Since the precession frequencies are magnetic field dependent, so also will be the amount of polarization conserved in the reaction products.

The theory of muon spin polarization during chemical reaction is well developed [23-29], but exceeds the bounds of this introductory article. For illustrative purposes, however, the results for the simple case of the onestep reaction muonium $\rightarrow$ diamagnetic products are depicted in Fig. 8. $P_{D}$ is the polarization conserved in the diamagnetic products (termed "residual" polarization in the literature), assuming an initial muonium fraction of unity.

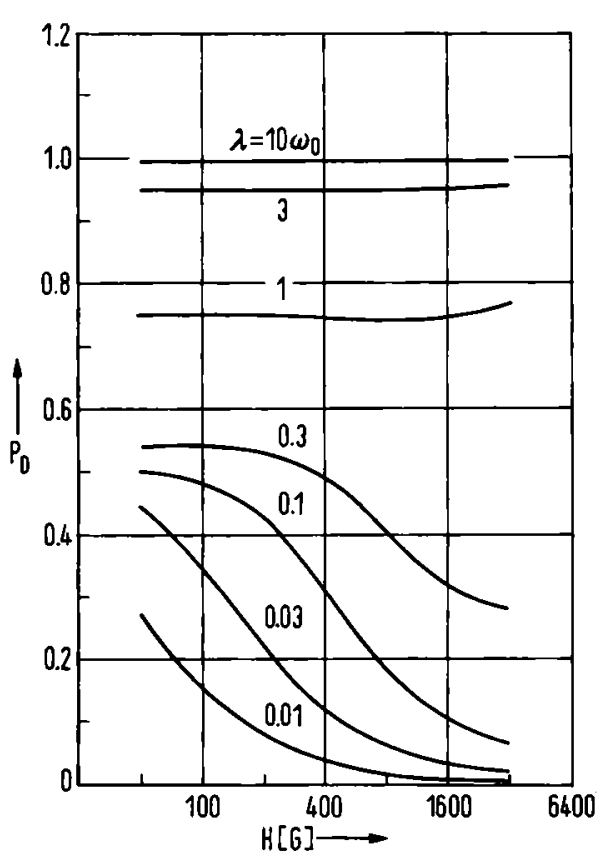

Fig. 8. Magnetic field dependence of the residual muon polarization conserved in the products of the one-step reaction: muonium $\rightarrow$ diamagnetic products. The reaction rates $\lambda$ are given as multiples of the muonium hy perfine frequency $\left(2.8 \times 10^{10}\right) \mathrm{s}^{-1}$

\section{Applications: Historical background}

Muonium was first detected by HuGHES et al. [10], using a high pressure argon gas target. The discovery formed part of a long series of experiments principally concerned with the determination of the muonium hyperfine interval by a number of different methods [30]. An extension of this work led to the first muonium kinetics studies; the decay of the muonium signal in argon was monitored in the presence of trace amounts of reactant gases [31]. A major experimental difficulty was the high momentum muon source (Columbia University Nevis Synchrocyclotron), which necessitated the use of gas pressures of the order of $50 \mathrm{~atm}$. to obtain muon stop rates up to $10^{2} \mathrm{~s}^{-1}$. It is therefore not surprising that the first systematic studies on gases had to await the development of the low momentum Arizona beam (muon stop rates $\sim 10^{4} \mathrm{~s}^{-1}$ in gas targets at atmospheric pressure) at the Lawrence Berkeley Laboratory [32]. This work has been continued at TRIUMF [33-35], and indeed still forms the major part of the muonium chemistry programme there.

Muonium chemistry in the condensed phase developed in parallel to the gas phase studies, but at other establishments. It was known from the earliest experiments with stopped muons [36-38] that the muon polarization (at the diamagnetic frequency) depends on the stopping medium. The existence of short-lived muonium figured amongst the first suggestions as to the cause of this phenomenon. The hypothesis was taken up by a number of scientists in the USSR, who proceeded to lay the foundations [23, 24, 39] of the theory of muon spin polarization. Experiments at Dubna soon accompanied theoretical developments, the main emphasis being on liquid phase chemistry [40]. In particular muonium reaction rate constants were extracted from measurements of the total diamagnetic fraction in pure organic compounds and binary mixtures. A comprehensive summary of all except the most recent russian work [41] may be found in the review by FIRSOV and GOLDANSKII [42]. The reader is cautioned, however, that the quantitative results must now be considered highly unreliable, due to the oversimplified models used in the analysis of experimental data. The "method of competing acceptors", for example, takes no account of the fact that there are often $t w o$ contributions to the measured diamagnetic fraction: an initial part arising from very fast radiolytic or hot atom processes, and the residual polarization from slower thermal reactions.

A far more sophisticated model was developed and applied by BREWER et al. at Berkeley in the early 70's [43-45]. The analysis included the phase as well as the amplitude of the diamagnetic precession signal, and multiple reaction paths involving muonic free radicals were also considered. Nevertheless, the complexity of the model makes it unsuited for the unequivocal determination of absolute rate constants, and indeed, certain of the results have been shown to be in error by several orders of magnitude [46]. 
The breakthrough in muonium reaction kinetics came with the detection of muonium in liquids [17] at one of the newly created meson factories. Unambiguous rate constant determinations are now routinely made at SIN and TRIUMF by direct measurements of muonium decay rates [46-48].

The most recent major development in muonium chemistry is the detection of muonic free radicals [49].

\section{Muonium kinetics in the gas phase}

In a continuing series of experiments FLEMING et al. [32-35] have determined rate constants for the reactions of muonium with $\mathrm{Br}_{2}, \mathrm{Cl}_{2}, \mathrm{~F}_{2}, \mathrm{HBr}, \mathrm{HCl}, \mathrm{HI}$ and $\mathrm{O}_{2}$ in the gas phase. The experimental procedure is as follows: Low energy (Arizona) muons are stopped in a moderator gas target set in a pair of Helmholtz coils. Although the gas pressure used is only slightly above atmospheric the $4.1 \mathrm{MeV}$ muons stop in about $25 \mathrm{~cm}$. (Energy is also lost by passage through various windows and the scintillator counter at the entrance to the gas cell.) Originally argon was used as the moderator, but more recently nitrogen has been used, since more muonium is formed in it. Muonium is detected by means of its precession in a low $(2-3 \mathrm{G})$ magnetic field. The addition of controlled amounts of reactant gas leads to decay of the signal, as demonstrated in Fig. 9. Up to a few million events are recorded for each reactant concentration, and the $\mu \mathrm{SR}$ histograms are analyzed by a multi-parameter least-squares fitting procedure to determine the decay rates $\lambda$. In the course of an experiment $10^{8}-10^{9}$ muons are stopped in the target, having negligible effect on the substrate concentration. The reaction rate is accordingly pseudo-first order:

$$
\lambda=\lambda_{0}+k[S]
$$

where $\lambda_{0}$ is the decay rate in the absence of the reactant and the bimolecular rate constant $k$ is given by the slope of a plot of $\lambda$ against concentration $[S]$ (Fig. 10).

The results to date are summarized in table 2 , where they

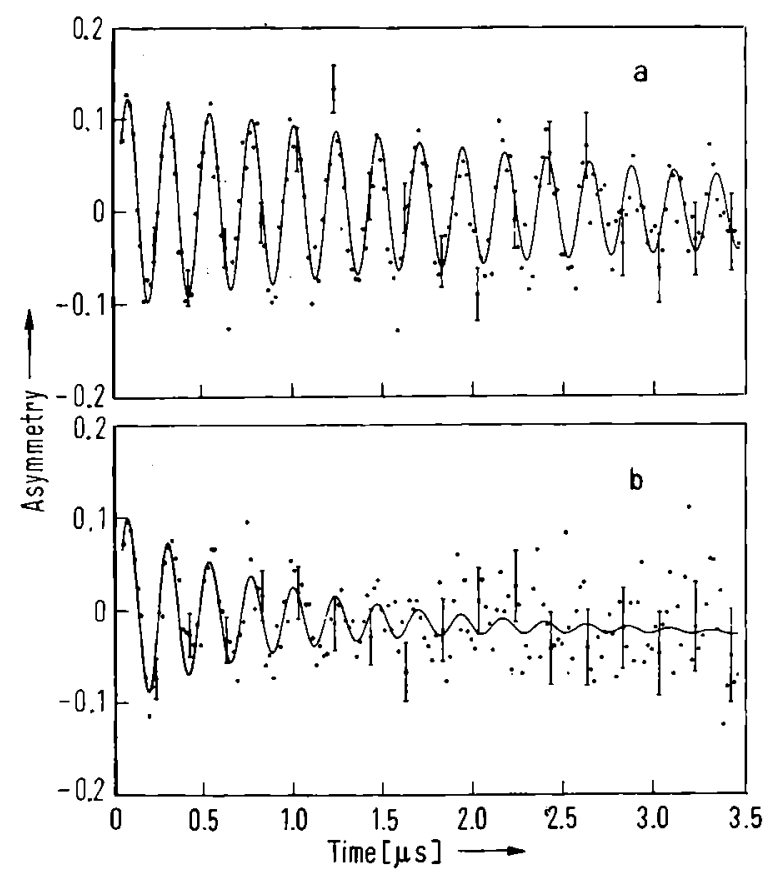

Fig. 9. Muonium precession signals in a) pure argon gas, and b) $1.89 \times 10^{-5} \mathrm{M} \mathrm{Cl}_{2}$ in argon (FLEMING et al. [33])

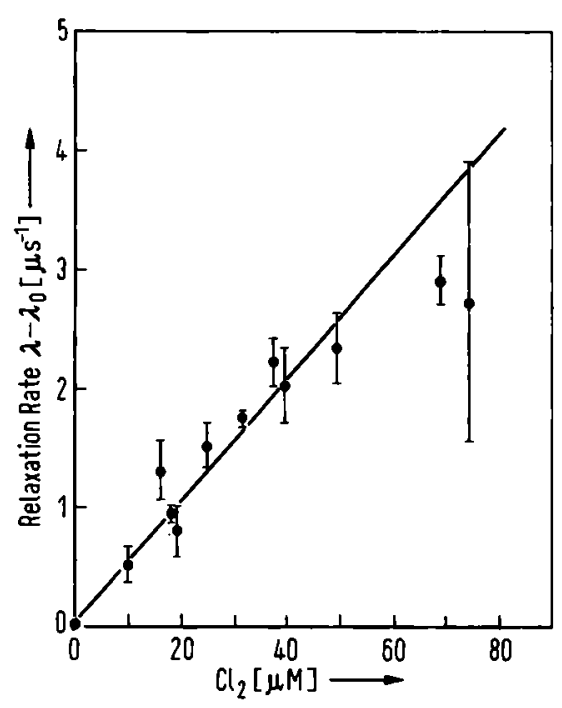

Fig. 10. Relaxation (decay) rates of muonium signals in argon as a function of added $\mathrm{Cl}_{2}$ concentration (FLEMING et al. [33])

Table 2. Reaction rate parameters for $M u$ and $H$ in the gas phase

\begin{tabular}{|c|c|c|c|c|c|}
\hline \multirow[b]{2}{*}{ Substrate } & \multicolumn{2}{|c|}{ Muonium $a$} & \multicolumn{2}{|c|}{ Hydrogen $b$} & \multirow[b]{2}{*}{$k_{\mathrm{M}} / k_{\mathrm{H}}(295 \mathrm{~K})$} \\
\hline & $\begin{array}{c}k(295 \mathrm{~K}) \\
{\left[10^{10} \mathrm{M}^{-1} \mathrm{~s}^{-1}\right]}\end{array}$ & $\begin{array}{c}E_{a} \\
\left\{\mathrm{~kJ} \mathrm{~mol}^{-1}\right\}\end{array}$ & $\begin{array}{c}k(295 \mathrm{~K}) \\
{\left[10^{10} \mathrm{M}^{-1} \mathrm{~s}^{-1}\right]}\end{array}$ & $\begin{array}{c}E_{a} \\
{\left[\mathrm{~kJ} \mathrm{~mol}^{-1}\right]}\end{array}$ & \\
\hline $\begin{array}{l}\mathrm{F}_{2} \\
\mathrm{Cl}_{2} \\
\mathrm{Br}_{2} \\
\mathrm{HCl} \\
\mathrm{HBr} \\
\mathrm{HI} \\
\mathrm{O}_{2}\end{array}$ & $\begin{array}{c}1.4 \pm 0.1 \\
5.1 \pm 0.2 \\
24 \pm 3 \\
\leqslant 0.00003 c \\
0.9 \pm 0.1 \\
2.53 \pm 0.13 \\
16.0 \pm 0.07 d\end{array}$ & $\begin{array}{l}3.9 \pm 1.0 \\
5.7 \pm 0.9\end{array}$ & $\begin{aligned} 0.08 & -0.25 \\
0.4 & -2.3 \\
2.2 & \pm 1.5 \\
0.0042 & \pm 0.0002 \\
0.21 & \pm 0.02 \\
0.86 & \pm 0.39\end{aligned}$ & $\begin{array}{c}8.8-10.9 \\
4.4-9.6 \\
4.2 \pm 2.1 \\
13.0 \pm 1.3 \\
10.9 \pm 0.4 \\
5.0 \pm 1.7\end{array}$ & $\begin{array}{c}5-19 \\
2-13 \\
6-39 \\
<0.007 \\
3.5-5.3 \\
1.9-5.7\end{array}$ \\
\hline $\begin{array}{ll}a & \text { taken } \\
b & \text { there a } \\
c & \text { upper } \\
d & \text { probab }\end{array}$ & $\begin{array}{l}\text { FLEMING et } \\
\text { ften discrepan } \\
\text { only } \\
\text { pin exchange, }\end{array}$ & $\begin{array}{l}{[4]} \\
\text { in the lite } \\
\text { chemical }\end{array}$ & or individual val & nd citatio & ee FLEMING et al. \\
\hline
\end{tabular}


are compared with hydrogen atom data. In addition to room temperature measurements, experiments have been performed at elevated temperatures for $\mathrm{F}_{2}$ and $\mathrm{Cl}_{2}$, and activation energies $E_{a}$ determined. The reaction with halides is clearly

$$
\mathrm{Mu}+\mathrm{X}_{2} \rightarrow \mathrm{MuX}+\mathrm{X}
$$

but it is not possible to distinguish between the two possibilities for the hydrogen halides:

$$
\mathrm{Mu}+\mathrm{HX} \rightarrow \mathrm{MuX}+\mathrm{H}
$$

and

$$
\mathrm{Mu}+\mathrm{HX} \rightarrow \mathrm{MuH}+\mathrm{X}
$$

For the analogous $\mathrm{H}$ atom reactions (12) is greatly favoured over (11), and this should also be the case for $\mathrm{Mu}$. The chemical reaction expected with oxygen is addition, but as this would necessitate three body encounters to remove excess energy a simple spin exchange process is deemed the more likely.

Despite the large uncertainties and discrepancies in the available $\mathrm{H}$ atom data, it can be seen from table 2 that, excepting $\mathrm{HCl}$, reaction with $\mathrm{Mu}$ is faster than with $\mathrm{H}$. The Simple Collision Theory of bimolecular reactions [50] states that

$$
k=\sigma \bar{v} \exp \left(-E_{\min } / R T\right)
$$

The collisional cross-section $\sigma$ is a geometrical quantity, and should be the same for $\mathrm{Mu}$ and $\mathrm{H}$. However, the mean relative velocity $\bar{v}$ is inversely proportional to the square root of the reduced mass for the collision partners. Thus, for reactions of $\mathrm{Mu}$ and $\mathrm{H}$ with much heavier atoms and molecules, $\bar{v}$ will be three times larger for Mu than for $\mathrm{H}$. $E_{\min }$ is the minimum energy necessary for reaction, and is related to the experimental activation energy by

$$
E_{a}=E_{\min }+\frac{1}{2} R T .
$$

Although the experimental values of $E_{a}$ for the fluorine reactions clearly show that $E_{\min }$ is isotope dependent, further analysis on these lines is unrewarding, since Collision Theory provides no way of calculating $E_{\min }$ independently. Instead one must turn to the more sophisticated theories of molecular dynamics.

In terms of the energy dependent reaction cross-section $S(\epsilon)$, the rate constant at temperature $T$ is given by [50]

$k(T)=(2 N / R T)^{3 / 2}(\pi \mu)^{-1 / 2} \int_{0}^{\infty} S(\epsilon) \epsilon \mathrm{e}^{-\epsilon N / R T} \mathrm{~d} \epsilon$.

Once again a trivial isotope effect arises from the reduced mass dependence. Deviations from this value are assigned to differences in $S(\epsilon)$. Unfortunately, it is impossible to deduce information about reaction cross-sections from experimental rate constants. Instead, it is necessary to compute individual values of $S(\epsilon)$ with the aid of some suitable theory, before (15) can be integrated and compared with experiment. CONNOR et al. $[51,52]$ have performed just such computations for the reactions of $\mathrm{Mu}$, $\mathrm{H}, \mathrm{D}$ and $\mathrm{T}$ with $\mathrm{F}_{2}$. Their results emphasize the importance of tunnelling at room temperature, and confirm the existence of the "light atom anomaly" - the low degree of product vibrational excitation. They find $k_{\mathrm{Mu}} / k_{\mathrm{H}}=5.9$ at $300 \mathrm{~K}$, apparent activation energies of 4.6 and $8.8 \mathrm{~kJ} \mathrm{~mol}^{-1}$ for $\mathrm{Mu}$ and $\mathrm{H}$, respectively, and $v^{\prime}=1$ as the most populated product vibrational state for the muonium reaction.

\section{Muonium kinetics in aqueous solution}

Rate constants for the reactions of muonium in aqueous solution have been determined in a manner entirely analogous to the gas phase studies [46-48]. The measurements suffer, however, from the small muonium fraction observable in water $(20 \%)$ [46], compared with that in argon $(\sim 80 \%)$ and nitrogen gases $(\sim 100 \%)^{1}[14]$ (cf. Figs. 9 and 11). The results are gathered together in table 3 , where they are compared with hydrogen atom data [53]. In addition to the data of table 3 , upper limits of $10^{-7}$ $\mathrm{M}^{-1} \mathrm{~s}^{-1}$ or less have been deduced for the reactions with $\mathrm{H}^{+}, \mathrm{Na}^{+}, \mathrm{K}^{+}, \mathrm{Zn}^{2+}, \mathrm{Cl}^{-}, \mathrm{ClO}_{4}^{-}$and $\mathrm{SO}_{4}^{2-}$.

The highest rate constants so far determined are those for the reactions with $\mathrm{MnO}_{4}^{-}$and $\mathrm{Ag}^{+}$, assumed by analogy with $\mathrm{H}$ to be simple redox processes, e. $\mathrm{g}$.

$$
\mathrm{Mu}+\mathrm{MnO}_{4}^{-} \rightarrow \mu^{+}+\mathrm{MnO}_{4}^{2-}
$$

The rates of both the $\mathrm{Mu}$ and $\mathrm{H}$ reactions are probably diffusion limited, and as such depend on the reaction diameters and diffusion constants of the reactants. These parameters are primarily determined by geometrical factors (and not isotopic mass), so that in these cases no

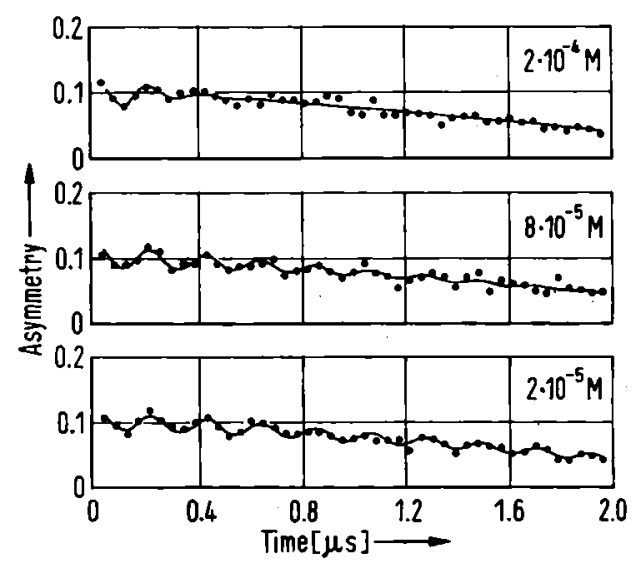

Fig. 11. Muonium signals from aqueous solutions of fumaric acid

1 The data from ref. [14] has been corrected for the effect of muons which stop in the walls of the gas cell. 
Table 3. Comparison of rate constants for Mu and $H$ in aqueous solution ${ }^{a}$

\begin{tabular}{|c|c|c|c|}
\hline & $\underset{\left[\mathrm{M}^{-1} \mathrm{~s}^{-1}\right]}{k_{\mathrm{M}}}$ & $\underset{\left[M^{-1} s^{-1}\right]}{k_{H}}$ & $\frac{k_{\mathrm{H}}}{k_{\mathrm{M}}}$ \\
\hline \multicolumn{4}{|l|}{ diffusion controlled } \\
\hline $\begin{array}{l}\mathrm{MnO}_{\mathbf{4}}^{-} \\
\mathrm{Ag}^{+}\end{array}$ & $\begin{array}{l}2.5 \times 10^{10} \\
1.6 \times 10^{10}\end{array}$ & $\begin{array}{l}2.4 \times 10^{10} \\
1.15 \times 10^{10}\end{array}$ & $\begin{array}{l}1 \\
0.7\end{array}$ \\
\hline $\begin{array}{l}\text { H abstraction } \\
\text { methanol } \\
\text { ethanol } \\
\text { isopropanol } \\
\text { sec. butanol } \\
\text { HCOO- }\end{array}$ & $\begin{aligned}< & 3 \times 10^{4} \\
< & 3 \times 10^{5} \\
\simeq & 7 \times 10^{5} \\
& 1.1 \times 10^{6} \\
& 7.8 \times 10^{6}\end{aligned}$ & $\begin{array}{l}2.5 \times 10^{6} \\
2.1 \times 10^{7} \\
6.8 \times 10^{7} \\
1.3 \times 10^{8} \\
1.24 \times 10^{8}\end{array}$ & $\begin{array}{r}>83 \\
>70 \\
100 \\
118 \\
16\end{array}$ \\
\hline $\begin{array}{l}\text { Br abstraction } \\
\text { bromoacetic acid (pH 1) } \\
\text { 2-bromopropionic acid (pH 1) } \\
\text { 3-bromopropionic acid ( } \mathrm{pH} 1)\end{array}$ & $\begin{array}{r}1.5 \times 10^{9} \\
4.0 \times 10^{9} \\
\simeq \quad 3 \times 10^{8}\end{array}$ & $\begin{array}{l}2.6 \times 10^{8} \\
9.5 \times 10^{8} \\
1.7 \times 10^{8}\end{array}$ & $\begin{array}{l}0.17 \\
0.24 \\
0.6\end{array}$ \\
\hline $\begin{array}{l}H \text { addition to olefins } \\
\text { maleic acid }(\mathrm{pH} 1) \\
\text { fumaric acid }(\mathrm{pH} 1) \\
\text { ascorbic acid }(\mathrm{pH} 1) \\
\text { dihydroxyfumaric acid (pH 1) }\end{array}$ & $\begin{array}{l}1.1 \times 10^{10} \\
1.4 \times 10^{10} \\
1.8 \times 10^{9} \\
4.5 \times 10^{7}\end{array}$ & $\begin{array}{r}6 \times 10^{8} \\
9 \times 10^{8} \\
1.1 \times 10^{8} \\
9 \times 10^{7}\end{array}$ & $\begin{array}{l}0.06 \\
0.06 \\
0.06 \\
2\end{array}$ \\
\hline $\begin{array}{l}\text { miscellaneous } \\
\text { acetone (pH 1) } \\
\mathrm{HO}^{-} \\
\mathrm{NO}_{3}^{-} \\
\text {phenol } \\
\text { o-nitrophenol } \\
\mathrm{Tl}^{+} \\
\mathrm{SCN}^{-}\end{array}$ & $\begin{array}{l}8.7 \times 10^{7} \\
1.7 \times 10^{7} \\
1.5 \times 10^{9} \\
7.2 \times 10^{9} \\
8.0 \times 10^{9} \\
8.2 \times 10^{8} \\
6.2 \times 10^{7}\end{array}$ & $\begin{aligned} 2.8 & \times 10^{6} \\
1.5 & \times 10^{7} \\
9 & \times 10^{6} \\
2 & \times 10^{9} \\
3 & \times 10^{9} \\
1.2 & \times 10^{8} \\
2.7 & \times 10^{8}\end{aligned}$ & $\begin{array}{l}0.03 \\
1 \\
0.006 \\
0.28 \\
0.38 \\
0.15 \\
4.4\end{array}$ \\
\hline
\end{tabular}

a taken from PERCIVAL et al. [5], with the exception of the last four entries (JEAN et al. [48]).

kinetic isotope effects are expected. It is interesting to note that the positronium reaction with $\mathrm{MnO}_{4}^{-}$also bears the same rate constant [54].

The other entries in table 3 are for activated reactions. Included are, by analogy with $\mathrm{H}[6,53]$ : hydrogen atom abstraction, bromine abstraction, addition to olefinic double bonds, and the miscellaneous reactions

$$
\begin{aligned}
& \mathrm{Mu}+\left(\mathrm{CH}_{3}\right)_{2} \mathrm{CO} \rightarrow\left(\mathrm{CH}_{3}\right)_{2} \dot{\mathrm{COMu}} \\
& \mathrm{Mu}+\mathrm{OH}^{-} \rightarrow \mathrm{MuOH}+\mathrm{e}_{\mathrm{aq}}^{-} \\
& \mathrm{Mu}+\mathrm{NO}_{3}^{-} \rightarrow \mathrm{MuO}^{-}+\mathrm{NO}_{2} \\
& \mathrm{Mu}+\mathrm{C}_{6} \mathrm{H}_{5} \mathrm{OH} \rightarrow \mathrm{C}_{6} \mathrm{H}_{5} \mathrm{MuOH} \\
& \text { and } \mathrm{Mu}+\mathrm{SCN}^{-} \rightarrow \mathrm{MuSCN}^{-} \text {. }
\end{aligned}
$$

Most of the reactions show marked isotope effects; hydrogen abstraction is slower for muonium, whilst bromine abstraction and most of the addition reactions are faster.

RODUNER et al. [47] have applied the results of Transition State Theory [50] to interpret the kinetic isotope effects. The rate constant is given by

$$
k=\Gamma \frac{R T}{N h} \frac{Q^{\ddagger}}{Q_{\mathrm{A}} Q_{\mathrm{i} 3}} \exp \left(-\frac{E^{\ddagger}}{R T}\right)
$$

where $\Gamma$ is the transmission factor (primarily due to the effect of tunnelling); $Q_{\mathrm{A}}, Q_{\mathrm{B}}$ and $Q^{\ddagger}$ are the relevant molecular partition coefficients for reactants and transi- tion state; and $E^{\ddagger}$ is the activation energy. It should be noted that, although a common potential energy surface is usually assumed for isotopic reactions (ignoring the small differences that arise from non-adherence to the Born-Oppenheimer Principle), the activation energy $E^{\ddagger}$ is generally isotope dependent, since zero-point vibrations in the reactants and transition state must be taken into account. Differences in $E^{\ddagger}$ and $\Gamma$ constitute the most important contributions to the isotope effect.

For the hydrogen abstraction reactions of $\mathrm{Mu}$ and $\mathrm{H}$ differences in $E^{\ddagger}$ arise solely in the transition state; the larger zero-point energy for muonium leads to slower reaction, in accord with experimental findings. (N. B. There is no conflict with the well-known result that abstraction of $\mathrm{H}$ is faster than abstraction of $\mathrm{D}$. In this case the zeropoint energy difference is greater in the reactants.)

RODUNER et al. [47] have performed BEBO calculations to characterize the transition states, and thus calculate the $E^{\ddagger}$ differences. The predictions were found to account for the major part of the observed isotope effects, and so it was deduced that tunnelling must play only a minor role. More recent work suggests otherwise, however $[55,56]$.

The influence of tunnelling is very difficult to estimate, in view of the large theoretical uncertainties involved. For a given barrier shape and size muonium will clearly be favoured over hydrogen, but it would be naive to expect quantitative predictions by simple evaluation of 
Table 4. Hyperfine coupling constants of muonic radicals and comparison with H-analogues $a$

\begin{tabular}{|c|c|c|c|c|}
\hline parent compound & assumed radical & $A_{\mu}[\mathrm{MHz}]^{b}$ & $A_{\mu} \cdot \frac{\mu_{p}}{\mu_{\mu}}[\mathrm{MHz}]$ & $A_{p}[\mathrm{MHz}]^{c}$ \\
\hline acetone & $\left(\mathrm{CH}_{3}\right)_{2} \dot{\mathrm{COMu}}$ & 26.0 & 8.2 & $0.90(300)$ \\
\hline 2-methylpropene & $\left(\mathrm{CH}_{3}\right)_{2} \dot{\mathrm{C} C H}{ }_{2} \mathrm{Mu}$ & 292.0 & 91.7 & $63.7 \quad(300)$ \\
\hline 2,3-dimethyl-2-butene & $\left(\mathrm{CH}_{3}\right)_{2} \mathrm{CMuC}\left(\mathrm{CH}_{3}\right)_{2}$ & 160.9 & 50.5 & 30.18 \\
\hline 2-methylbutadiene & $\left\{\begin{array}{l}\mathrm{CH}_{2}=\mathrm{C}\left(\mathrm{CH}_{3}\right) \mathrm{CHCH}_{2} \mathrm{Mu} \\
\mathrm{CH}_{2} \mathrm{MuC}\left(\mathrm{CH}_{3}\right) \mathrm{CH}=\mathrm{CH}_{2}\end{array}\right.$ & $180.7 / 199.5$ & $56.8 / 62.7$ & $\begin{array}{ll}37.8 & (300) \\
42.9 & (363)\end{array}$ \\
\hline 1,3-pentadiene & $\left\{\begin{array}{l}\mathrm{CH}_{2}=\mathrm{CHCHCHMuCH} \\
\mathrm{CH}_{2} \mathrm{MuCHCH}=\mathrm{CHCH}_{3}\end{array}\right.$ & $169.0 / 182.7$ & $53.1 / 57.4$ & $\begin{array}{l}39.74(140) \\
-\end{array}$ \\
\hline benzene & cyclohexadienyl & 514.6 & 161.6 & $133.71(288)$ \\
\hline benzene-d 6 & cyclohexadienyl-d 6 & 520.1 & 163.4 & 135.9 \\
\hline thiophene & 2-thiophenyl & 338.9 & 106.5 & $95.3(130)$ \\
\hline
\end{tabular}

standard formulae. Choice of the proper reduced mass to use in the calculations is no trivial problem [57], and anyway the energy barrier of hydrogen abstraction is higher for muonium, thus reducing the expected tunnelling contribution [55].

\section{Muonic free radicals}

Only recently has the nature of, and thence the means to observe muonic radical spectra become fully understood [49]. Since then radicals have been detected in liquid samples of a number of organic compounds. The parent molecules giving rise to muonic radicals all contain some degree of unsaturation: a carboxyl group (acetone), a carbon-carbon double bond (e.g. 2-methylpropene), conjugated double bonds (e.g. pentadiene), or an aromatic ring (e. g. benzene). In each case the radicals observed are assumed to be those formed by formal addition of muonium, as depicted in table 4 . Where more than one radical adduct is possible (e. g. for thiophene) assignment is made in analogy with the known chemistry of the hydrogen atom. Even then, it is not possible to distinguish between the pairs of conjugated radicals formed from the dienes. It is significant, however, that only two radicals are observed in such càses (e. g. from 2-methyl-1,3-butâdiene, see Fig. 12), and not all four possibilities, as would be the case for non-selective addition.

As mentioned in Section 3.3, the muon-electron hyperfine coupling constant may be readily measured from a radical spectrum; it is merely given by the difference between the two radical frequencies observed at high field, due account being taken of their polarity. In table 4 the coupling constants are compared with those of the hydrogen atom analogues [58]. In the absence of isotope effects the muon and proton hyperfine constants should be in the ratio of their magnetic moments, $\mu_{\mu} / \mu_{P}=3.1833$. The discrepancies between the last two columns of table 4 clearly demonstrate the existence of isotope effects. In all cases the muon coupling constant is larger than predicted solely from the relative magnetic moments. The explanation is based on arguments proposed to explain similar isotope effects observed when $H$ is replaced by $D[59,60]$ Due to the nature of radical addition, the hyperfine constants are of the " $\beta$ " type, i. e. the muonium atom is bound to an atom adjacent to the radical centre (or con-

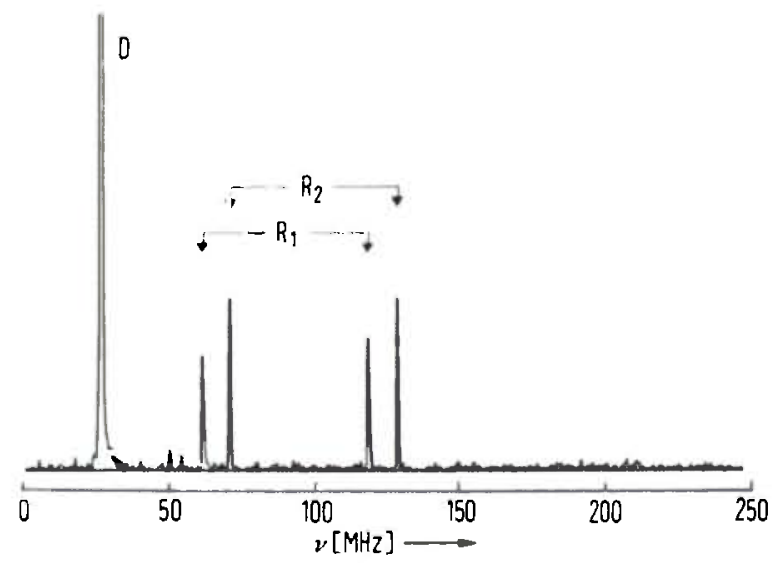

Fig. 12. Fourier transform of the precession signals from 2-methyl1,3 butadiene at $2 \mathrm{kG}$

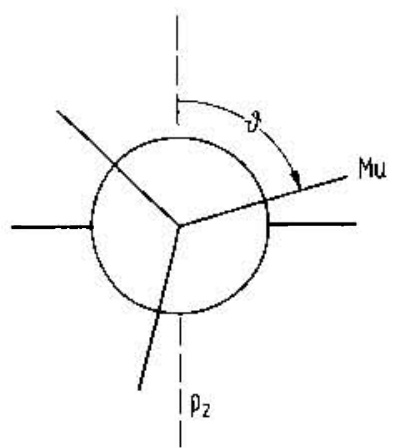

Fig. 13. Definition of the dihedral angle $\theta$ 
jugated system). Such constants $A_{\beta}$ are known to vary with the dihedral angle $\theta$ (see Fig. 13) between the bond to the muonium atom and the axis of symmetry of the p-orbital (plane of $\pi$-system) containing the unpaired electron:

$$
A_{\beta}(\theta)=B_{0}+B_{1} \cos ^{2} \theta
$$

$B_{0}$ and $B_{1}$ are constants; $B_{1}$ is usually much larger than $B_{0}$, and typically takes the value $140 \mathrm{MHz}$ for proton coupling in alkyl radicals. The value of $A_{\beta}$ determined by experiment depends on the expectation value $\left\langle\cos ^{2} \theta\right\rangle$, which takes the value $1 / 2$ in the high temperature limit, where all values of $\theta$ are equally probable, i. e. there exists free rotation about the bond joining the $\alpha$ and $\beta$ atoms. In general, the probability of a given value of $\theta$ depends on the potential energy of the conformation and the temperature. Conformers with $\theta \simeq \pi / 2$ have eclipsed substituents, and the increased zero-point vibrational motion in muonic radicals leads to higher potential energy (steric hindrance). Thus these conformers, which have the lowest values of $A_{\beta}(\theta)$, are less probable for muonic radicals at a given temperature, and higher mean values $\left\langle A_{\beta}\right\rangle$ ensue.

Although rotation as described above can be excluded for small ring systems, such as in the cyclohexadienyl radical, the same considerations apply to the effect of non-equivalent sites resulting from out-of-plane deformations of the ring [61].

Another promising field of investigation with muonic radicals, albeit one still in its infancy, is radical kinetics. In contrast to muonium kinetics only minor or negligible kinetic isotope effects are to be expected (except where reaction is at the $\mathrm{Mu}$ site). Muonium would therefore merely act as a tracer atom, and could find application in radical reactions difficult or even impossible to study by other means.

\section{Early events in muonium chemistry}

\subsection{Information from signal amplitudes}

The term "early events" is used here to designate the physico-chemical processes that lead to the distribution of muon spin polarization amongst the various muonic species and their individual precession frequencies. Included are the means of formation of muonium, radicals and diamagnetic compounds, radiolytic and epithermal reactions, and fast depolarization processes. All these processes occur at times short compared with that necessary for direct $\mu$ SR detection (i. e. $t<10^{-7} \mathrm{~s}$ ), so that the available information is contained in the initial amplitudes of the $\mu$ SR precession frequencies. The measured amplitudes are usually scaled to give the fractional polarizations $P_{\mathrm{D}}, P_{\mathrm{M}}$ and $P_{\mathrm{R}}$ by comparison with a standard $\left(P_{\mathrm{D}}=1.0\right.$ for $\mathrm{CCl}_{4}$ ). In the ideal case the polarizations directly represent the distribution of muons, designated $h_{\mathrm{D}}, h_{\mathrm{M}}$
Table 5. Some representative muon fractions

\begin{tabular}{lccc}
\hline & $h_{\mathrm{D}}$ & $h_{\mathrm{M}}$ & $h_{\mathrm{R}}$ \\
\hline water & 0.62 & $0.38^{a}$ & 0 \\
ice $(T>160 \mathrm{~K})$ & 0.48 & 0.52 & 0 \\
methanol & 0.61 & $(0.39)^{b}$ & 0 \\
acetone & 0.55 & 0 & $(0.45)^{c}$ \\
benzene & 0.22 & 0 & $(0.78)^{c}$ \\
aluminium & 0.99 & 0 & 0
\end{tabular}

$a$ from $\mathrm{NO}_{3}^{-}$scavenging experiments; observed $P_{\mathrm{M}}=0.20$

$b$ assumed value; observed $P_{M}=0.19$

$c$ assumed value; $P_{\mathrm{R}}$ difficult to determine

and $h_{\mathrm{R}}$; but only in the absence of depolarization. Some representative muon fractions are given in table 5 .

As pointed out in Section 3.4 reactions of muonic species lead in general to depolarization. This is particularly important for muonium. Thus many free radical scavengers employed in radiolysis studies (Section 8.3 ) react with thermalized muonium with the result that its signal is quenched $\left(P_{\mathrm{M}}=0\right)$. If the rate is high enough part of the polarization will be carried over into the reaction products. In this case the measured $P_{\mathrm{D}}$ will be a sum of the initial fraction $h_{\mathrm{D}}$ and the residual polarization $P_{\text {res }}$. The two contributions may be separated by exploiting the magnetic field dependence of $P_{\text {res }}$ (Fig. 8). Detailed description of such analyses may be found in a recent paper by PERCIVAL et al. [62]. Application has so far been limited to aqueous systems.

Polarization may also be lost by purely physical processes - spin relaxation. The decay of both diamagnetic $[63,64]$ and muonium [65] signals has been followed in solutions of paramagnetic ions. As is well known in magnetic resonance [66], coupling of the magnetic moments of the ion and the muonic species provides a pathway for total polarization loss via fast spin-lattice relaxation inherent in the ion. If depolarization is fast enough no precession signal remains. Nevertheless, it is also possible for spin relaxation to lead to a reduction in signal amplitudes without altering the observed lifetimes - but only if the interacting paramagnetic species is transient. Free radicals produced as a result of radiolysis fulfil this condition, and are thought to be the cause of the so-called "missing fraction" of polarization in water and alcohols (Section 8.3). The mechanism differs from that involving paramagnetic ions in that the transient radicals do not exhibit efficient spin-lattice relaxation. Coupling of the spins results in transfer of part of the polarization to the undetected species; no polarization is lost to the lattice.

\subsection{Muonium formation in gases}

The fraction of muons that thermalize as muonium has been measured for several inert gases, both at high [12] and low $[13,14]$ pressures. There is general agreement that no muonium forms in helium and neon, a large fraction is found in argon, and that even more (perhaps the 
total $\mu^{+}$fraction is neutralized) is formed in xenon and nitrogen. The quantitative discrepancies in the literature $\left(0.63 \leqslant h_{\mathrm{M}} \leqslant 0.85\right.$ for Ar) are attributable to two experimental difficulties: (1) the diffuse nature of the stopping medium leads to a large spread of stopping sites, so that reliable calibration of signal amplitudes in terms of polarization fractions is virtually impossible; and (2) the diamagnetic signal is likely to include a contribution from muon stops in the walls of the gas cell and in the detectors themselves.

In simple terms, electron capture during the slowing down of a heavy positive ion occurs when the velocity becomes comparable to that of orbital electrons in the stopping medium. This corresponds to a muon kinetic energy of several keV. Many electron loss-capture cycles take place before the final stopped state $\left(\sim 10^{2}\right.$ for $\left.\mu^{+}[30]\right)$, the nature of the final state depending particularly on the cross-sections of the charge-changing processes at low energy. These depend on charge and velocity only, so that the results of hydrogen beam studies [67] may be applied. Unfortunately, little or no data is available for the crucial low energy regime.

That muonium is formed from epithermal $\mu^{+}$is proven by its observation in argon and nitrogen, which have ionization potentials 15.8 and $15.6 \mathrm{eV}$, respectively [I. P. $(\mathrm{Mu})=$ $13.54 \mathrm{eV}]$. Furthermore, any thermal reaction would give rise to a relaxation of the diamagnetic signal in argon. However, it has been suggested [14] that $\mu^{+}$survival in noble gases is anyway unlikely since molecular ions of the type $\mathrm{Ne} \mu^{+}$are predicted to be stable; it was assumed, probably quite correctly, that these species will be formed at a rate faster than the muon decay.

Any attempt to apply the above gas phase concepts to muonium formation in liquids soon runs into difficulties. Collisions are much more frequent in condensed media, and may not be treated as isolated events. To estimate the muon stopping power in water MOZUMDER [68] made use of the experimental proton charge-changing crosssections in isoelectronic neon; but he also admits that the effective charge of a track particle is higher at low velocities in condensed media than that calculated on the basis of gas phase results. Because of this more radiolysis damage is to be expected towards the end of muon tracks in liquids. Due to its light mass the low energy muon/muonium will be markedly scattered by collisions with heavier nuclei and atoms, so escape (of neutral muonium) from regions of damage will not be so facile as was previously assumed [45]. Possible reactions of muons and muonium with radiolysis products in water are discussed in the following Section.

\subsection{Liquids: Radiolysis effects}

The polarizations of the two muon signals detected in pure water $\left(\mathrm{H}_{2} \mathrm{O}\right)$ are $P_{\mathrm{D}}=0.622 \pm 0.006$ and $P_{\mathrm{M}}=0.196$ \pm 0.003 [62]. It is remarkable that their sum is less than unity, in contrast to the results for ice, where $P_{\mathrm{D}}=0.480$ \pm 0.004 and $P_{M}=0.52 \pm 0.02$, above $160 \mathrm{~K}$. Scavenging studies with $\mathrm{NO}_{3}^{-}[62]$ have led to the conclusion that $h_{\mathrm{D}}=P_{\mathrm{D}}$, and that the missing fraction in water is due to depolarized muonium $\left(h_{\mathrm{D}}+h_{\mathrm{M}}=1\right)$.

High concentrations of $\mathrm{NO}_{3}^{-}$were further found to bring about an increase in $h_{\mathrm{D}}$, as was also the case for other powerful electron scavengers (Fig. 14) [62]. On the other hand, a reduction in $h_{\mathrm{D}}$ was found for high concentrations of $\mathrm{SCN}^{-}$, an efficient $\cdot \mathrm{OH}$ scavenger, although a second scavenger, $\mathrm{I}^{-}$, displayed more complex behaviour (Fig. 15) [69]. The results indicate that the muon distribution is governed by reactions of the muon (or muonium) with the chief transient radicals created in the radiolysis of water [70]. The high concentrations of scavengers required implies that the $h_{\mathrm{D}}: h_{\mathrm{M}}$ partitioning takes place at very short times, $t \lesssim 10^{-11} \mathrm{~s}$. Furthermore, the inactivity of high acid concentrations (up to $5 \mathrm{M}$ ) is consistent with the involvement of the dry electron. $\left(\mathrm{H}_{2} \mathrm{O}^{+}\right.$ is known to be ineffective in scavenging the precursor of $\mathrm{e}_{\mathrm{aq}}^{-}[71]$.) The hydrated electron, however, may well be the cause of the missing fraction, since this is scavengeable by $0.1 \mathrm{M} \mathrm{NO}_{3}^{-}$[62]. A reaction scheme inspired by the spur model of positronium formation $[54,72,73]$ is consistent with the above.

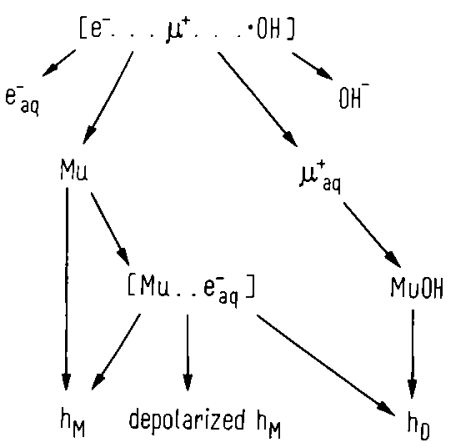

At the end of its track, in the so-called terminal spur, the muon is in the immediate neighbourhood (within a few $\mathrm{nm}$ ) of the radiolysis products $\mathrm{e}^{-}$and $\cdot \mathrm{OH}$. If the muon and electron combine muonium is formed, otherwise the muon will hydrate and end up substituted in a water molecule:

$$
\begin{aligned}
\mu^{+}+\mathrm{H}_{2} \mathrm{O} & \rightarrow \mathrm{MuOH}_{2}^{+} \\
\mathrm{MuOH}_{2}^{+}+\mathrm{H}_{2} \mathrm{O} & \rightarrow \mathrm{MuOH}+\mathrm{H}_{3} \mathrm{O}^{+} .
\end{aligned}
$$

Clearly removal of $\mathrm{e}^{-}$will result in less $h_{\mathrm{M}}$ and proportionately more $h_{\mathrm{D}}$. On the other hand scavenging of $\cdot \mathrm{OH}$, which competes with $\mu^{+}$for $\mathrm{e}^{-}$

$$
\cdot \mathrm{OH}+\mathrm{e}^{-} \rightarrow \mathrm{OH}^{-}
$$

increases the probability of muonium formation, and $h_{\mathrm{D}}$ is reduced. The analogous inhibition $[54,72,73]$ and enhancement [74] of positronium formation are well documented.

Once formed, muonium might react with a further radical (and so contribute to $h_{\mathrm{D}}$ ) or survive to be observed. A third possibility entails a non-reactive encounter with a transient radical, whereby spin polarization may be lost 


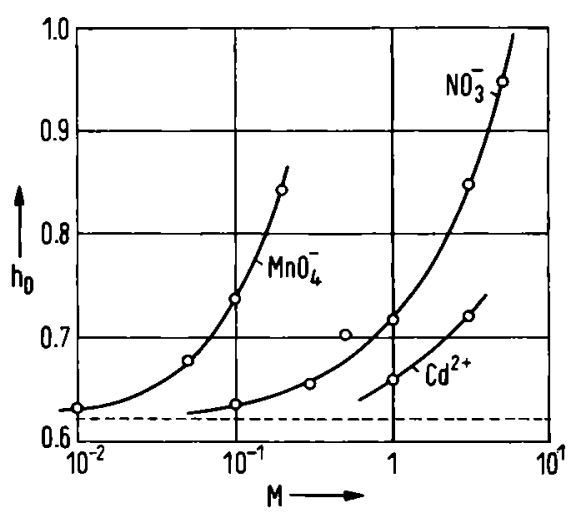

Fig. 14. Effect of electron scavengers on $h_{\mathrm{D}}$

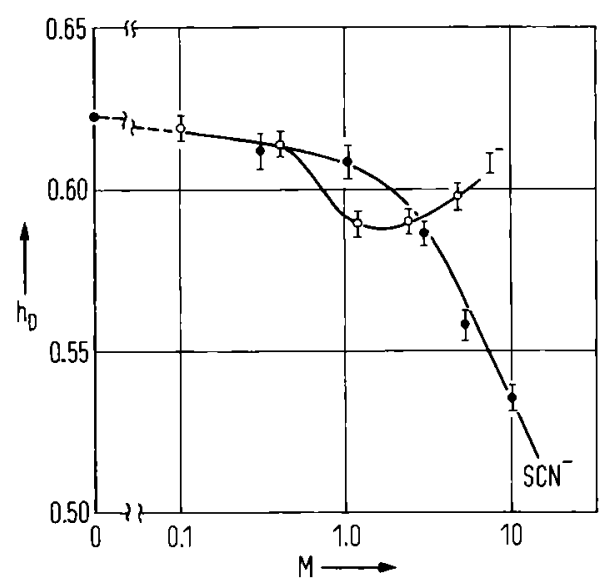

Fig. 15. Effect of $\cdot \mathrm{OH}$ scavengers on $h_{\mathrm{D}}$

(transferred to the radical's unpaired electron) in a manner not unlike the radical pair mechanism of chemically induced magnetic polarization [75].

In ice, hydration, or trapping processes are slower than in water, so it is not surprising that more muonium is formed. Similarly the reduced survival rate of electrons in ice [76] minimizes the chance of encounters which lead to the missing fraction.

The muon fractions in the simple alcohols (e. g. $\mathrm{MeOH}$, table 5) are very similar in magnitude to those of water, and the spur model should presumably also apply to these liquids. It is significant that $h_{\mathrm{D}}$ for ethanol is constant, with mean value $0.601 \pm 0.003$, from room temperature right down to the frozen state (unpublished results from this laboratory). This indicates that the processes which determine $h_{\mathrm{D}}$ are not in competition with electron and muon solvation. Electron solvation in ethanol requires $2.3 \times 10^{-11} \mathrm{~s}$ at $293 \mathrm{~K}$ and lasts up to $2 \times 10^{-7} \mathrm{~s}$ at $150 \mathrm{~K}$ $[77,78]$. The conclusion is that muonium formation takes place before electron solvation, as was suggested by the aqueous scavenging experiments. Analogous results from positronium formation [79] and picosecond pulse radiolysis [80] experiments have been explained in the same way.

\subsection{Hot atom chemistry?}

If muonium is formed at epithermal energies then the possibility of hot atom reactions must be considered. In fact, in earlier work [45] the whole of $h_{\mathrm{D}}$ was attributed to the diamagnetic products of such reactions. However, not only does the radiolysis model provide an alternative interpretation of $h_{\mathrm{D}}$, certain specific experimental results indicate that hot reactions can at most make a minor contribution in aqueous systems. Thus, freezing of water brings about a reduction in $h_{\mathrm{D}}$, with corresponding increase in the muonium fraction (table 5); the effect is even more marked for $\mathrm{D}_{2} \mathrm{O}$ [62]. These results are in strong contrast to the findings of recoil tritium studies $[81,82]$, as is the temperature dependence displayed by $h_{\mathrm{D}}$ below $160 \mathrm{~K}[62]$.

Finally, within the hot atom hypothesis the reduction in $h_{\mathrm{D}}$ found in $\mathrm{SCN}^{-}$scavenging experiments [69] would represent an increased efficiency of muonium thermalization - a most unlikely explanation.

A small contribution from hot reactions cannot be excluded on the basis of the above remarks, but the question still arises: Why are hot reactions so unimportant for muonium when $79 \%$ of recoil tritium atoms react in this fashion [81]? One point that may be of significance is that for a given kinetic energy (e. g. for which the tritium-water reaction has a large cross-section), the velocity of $\mathrm{Mu}$ is more than 5 times that of $T$. Perhaps the interaction time of a muonium atom and a water molecule is simply too short at those energies at which tritium reacts? It is significant that theoretical calculations for H, D and T show an isotope effect favouring the heaviest atom [83]. The evidence against hot reactions is at present restricted to aqueous systems, since only these have been subjected to intensive study [62]. FLEMING et al. [4] have analyzed the measured diamagnetic fractions in binary mixtures of organic liquids entirely in terms of hot reactions. Plots of $P_{\mathrm{D}}$ against volume fraction for $\mathrm{CH}_{3} \mathrm{OH} / \mathrm{CHCl}_{3}$ and $\mathrm{CH}_{3} \mathrm{OH} / \mathrm{C}_{6} \mathrm{H}_{6}$ were found to be linear, implying indiscriminate reactions of muonium. The explanation offered is that epithermal muonium has but a short time (i. e. narrow energy gap) during which reaction is possible, and that during this period it is essentially in contact with one molecule only.

The great difficulty with the hot atom hypothesis in muonium chemistry is that it is almost impossible to test it in any way. Quantitative theoretical models are strictly only applicable to the gas phase (where there is a dearth of muonium chemistry data), and anyway imply the existence of the perfect moderator - - which has yet to be discovered.

The problem is perhaps partly semantic [84], since the high electron density in condensed matter defies strict differentiation between an energetic atom and its positive ion.

The concerted epithermal process

$\mathrm{Mu}^{*}+\mathrm{H}_{2} \mathrm{O} \rightarrow \mu^{+}+\mathrm{H}+\mathrm{e}^{-}+\cdot \mathrm{OH}_{\rightarrow \mathrm{Mu}+\mathrm{H}_{2} \mathrm{O}}^{\rightarrow \mathrm{MuOH}+\mathrm{H}}$

has many characteristics of the radiolysis model described in Section 8.3, and recent pulse radiolysis results suggest that the dry electron is scavenged while still epithermal [80]. As is often the case in scientific disputes the issues become clouded in time. 


\section{Acknowledgements}

Discussions with my co-workers on the muonium chemistry project, Prof. H. FisCHER, Dr. J. HochmanN and E. RODUNER have contributed much to my understanding, and have thus made the writing of this review possible. I further thank Prof. FISCHER for his comments on early drafts of the manuscript. Support from the Swiss National Foundation for Scientific Research is acknowledged.

\section{References}

1. WEISSENBERG, A. O.: Muons, North-Holland, Amsterdam 1967.

2. HugheS, V. W., WU, C. S. (eds.): Muon Physics, Academic Press, New York 1975, vols. $1-3$.

3. SCHENCK, A.: On the Application of Polarized Positive Muons in Solid State Physics. In: Nuclear and Particle Physics at Intermediate Energies (1976) (J. B. WARREN, ed.) Plenum Publ. Corp., New York 1976.

4. Fleming, D. G., GARNER, D. M., VAZ, L. C., WALKER, D. C., BREWER, J. H., CROWE, K. M.: Muonium Chemistry - A Review. In: Positronium and Muonium Chemistry (H. J. ACHE, ed.) Advances in Chemistry Series, American Chemical Society, in press.

5. PERCIVAL, P. W., RODUNER, E., FISCHER, H.: Radiation Chemistry and Reaction Kinetics of Muonium in Liquids. In: Positronium and Muonium Chemistry (H. J. ACHE, ed.) Advances in Chemistry Series, American Chemical Society, in press.

6. NETA, P.: Reactions of Hydrogen Atoms in Aqueous Solutions. Chem. Rev. 72, 533 (1972).

7. JAKUBET Z, W.: Gas-phase Muonium Chemistry, Isotope Effects, and Collision Theory: Theoretical Investigations of the $\mathrm{Mu}+\mathrm{F}_{2}$ and $\mathrm{Mu}+\mathrm{Cl}_{2}$ Reactions and their Isotopic Counterparts. In: Proc. Ist. Int. Topical Meeting on Muon Spin Rotation, Rorschach, Sept. 1978, Hyperfine Interactions, in press.

8. URCH, D. S.: Chemical Reactions of Nuclear Recoil Particles in Gases and Liquids. In: Radiochemistry (A. G. MADDOCK, ed.) MTP Internat. Rev. Science, Inorg. Chem. Series Two, Vol. 8, Butterworths, London 1975, p. 49.

9. OLDERSHAW, G. A.: Reactions of Photochemically Generated Hot Hydrogen Atoms. In: Gas Kinetics and Energy Transfer, Vol. 2 (P. G. ASHMORE, R. J. DONOVAN, eds.) Chemical Society Specialist Periodical Reports, London 1977, p. 96.

10. HugheS, V. W., McCOLM, D. W., ZIOCK, K., PREPOST, R.: Formation of Muonium and Observation of its Larmor Precession. Phys. Rev. Letts. 5, 63 (1960).

11. Thompson, P. A., Amato, J. J., CRAne, P., Hughes, V. W., MObley, R. M., zu PUTlit z, G., Rothberg, J. E.: Determination of Muonium Hyperfine Structure Interval through Measurements at Low Magnetic Fields. Phys. Rev. Letts. 22, 163 (1969).

12. STAMbaUgh, R. D., CASPERSON, D. E., CRANE, T. W., HugheS, V. W., KASPAR, H. F., SOUDER, P., THOMPSON, P. A., ORTh, H., zu Putlit Z, G., DENison, A. B.: Muonium Formation in Noble Gases and Noble-Gas Mixtures. Phys. Rev. Letts. 33, 568 (1974).

13. BA RNETT, B. A., CHANG, C. Y., YODh, G. B., CAROLl, J. B., ECKHAUSE, M., HSIEH, C. S., KANE, J. R., SPENCE, C. B.: Muonium-Formation Measurements in Low Pressure Argon Gas. Phys. Rev. A 11, 39 (1975).

14. MikUla, R. J., GaRNER, D. M., Fleming, D. G., MARSHALL, G. M., BREWER, J. H.: Muonium Formation in Gases. In: Proc. 1st. Int. Topical Meeting on Muon Spin Rotation, Rorschach, Sept. 1978, Hyperfine Interactions, in press.

15. MYASISHCHEVA, G. G., OBUKHOV, YU. V., ROGANOV, V. S., FIRSOV, V. G.: A Search for Atomic Muonium in Che mically Inert Substances. Zh. Eksp. Teor. Fiz. 53, 451 (1967) [English trans. Sov. Phys. JETP 26, 298 (1968)].

16. GUREVICH, I. I., IVANTER, I. G., MELESHKO, E. A. NIKOLSKII, B. A., ROGANOV, V. S., SELIVANOV, V. I., SMILGA, V. P., SOKOLOV, B. V., SHESTAKOV, V. D.: Two-Frequency Precession of Muonium in a Magnetic Field.
Zh. Eksp. Teor. Fiz. 60, 471 (1971) [English trans. Sov. Phys. JETP 33, 253 (1971)].

17. Percival, P. W., Fischer, H., CAMANi, M., GYGAX, F. N., RUEGG, W., SCHENCK, A., SCHILLING, H., GRAF, H.: The Detection of Muonium in Water. Chem. Phys. Letts. 39, 333 (1976).

18. PERCIVAL, P. W.: discussion remarks. In: Radiation Effects in Liquids and Solids, Far. Disc. Chem. Soc. 63, 192 (1977).

19. BREWER, J. H., CROWE, K. M., GYGAX, F. N., JOHNSON, R. F., PATTERSON, B. D., FLEMING, D. G., SCHENCK, A.: Anomalous $\mu^{+}$Precession in Silicon. Phys. Rev. Letts. 31, 143 (1973).

20. PATterson, B. D., HINTERMANN, A., KUENDIG, W., MEIER, P. F., WALDNER, F., GRAF, H., RECKNAGEL, E., WEIDINGER, A., WICHERT, TH.: A nomalous Muonium in Silicon. Phys. Rev. Letts. 40, 1347 (1978).

21. GRAF, H., HOLZSCHUH, E., RECKNAGEL, E., WEIDINGER, A., WICHERT, TH.: Anomalous Muonium in Germanium. In: Proc. Ist. Int. Topical Meeting on Muon Spin Rotation, Rorschach, Sept. 1978, Hyperfine Interactions, in press.

22. ATHERTON, N. M.: Electron Spin Resonance, Ellis Horwood, Chichester 1973 , ch. 10 , p. 363.

23. NOSOV, V. G., YAKOVLEVA, I. V.: Depolarization of $\mu^{+}$ Mesons in Solids. Zh. Eksp. Teor. Fiz. 43, 1750 (1962) [English trans. Sov. Phys. JETP 16, 1236 (1963)].

24. IVANTER, I. G., SMILGA, V. P.: Theory of the Muonium Mechanism of Depolarization of $\mu^{+}$Mesons in Media. $\mathrm{Zh}$. Eksp. Teor. Fiz. 54, 559 (1968) [English trans. Sov. Phys. JETP 27, 301 (1968).]

25. IVANTER, I. G., SMILGA, V. P.: Contribution to the Theory of the Chemical Reactions of Muonium. Zh. Eksp. Teor. Fiz. 55, 1521 (1968) [English trans. Sov. Phys. JETP 28, 796 (1969)].

26. IVANTER, I. G., SMILGA, V. P.: The Theory of $\mu^{+}$-Meson Depolarization with Allowance for the Process of Charge Exchange or Formation of Unstable Chemical Compounds. $\mathrm{Zh}$. Eksp. Teor. Fiz. 60, 1985 (1971) [English trans. Sov. Phys. JETP 33, 1070 (1971)].

27. BREWER, J. H., GYGAX, F. N., FLEMING, D. G.: Mechanism for $\mu^{+}$Depolarization in Liquids - Muonium Chemistry with Radical Formation. Phys. Rev. A 8, 77 (1973).

28. FisCHER, W. E.: Muon Depolarization in Presence of Several Chemical Channels. Helv. Phys. Acta 49, 629 (1976).

29. PERCIVAL, P. W., FisCHER, H.: Theory and Analysis of $\mu^{+}$ Spin Polarization in Chemical Systems. Chem. Phys. 16, 89(1976).

30. Hughes, V. W., MCCOLM, D. W., ZIOCK, K., PrePOST, R.: Muonium I. Muonium Formation and Larmor Precession. Phys. Rev. A 1, 595 (1970) and 2, 551 (1970).

31. MOBLEY, R. M., BAILEY, J. M., CLELAND, W. E., HugheS, V. W., ROThBERG, J. E.: Muonium Chemistry. J. Chem. Phys. 44, 4354 (1966).

32. Fleming, D. G., BREWER, J. H., Garner, D. M., Pifer, A. E., Bowen, T., DElise, D. A., CROWE, K. M.: Muonium Chemistry in Gases: $\mathrm{Mu}+\mathrm{Br}_{2}$. J. Chem. Phys. 64, 1281 (1976).

33. Fleming, D. G., GARNER, D. M., BREWER, J. H., WARREN, J. B., Marshall, G. M., Clark, G., Pifer, A. E., BoWen, T.: The Chemical Reaction of Muonium with $\mathrm{Cl}_{2}$ in the Gas Phase. Chem. Phys. Letts. 48, 393 (1977).

34. Fleming, D. G., BREWER, J. H., GARNER, D. M.: Muonium Chemistry in the Gas Phase. Ber. Bunsenges. Phys. Chem. 81,159 (1977).

35. Garner, D. M., Fleming, D. G., Brewer, J. H.: Muonium Chemistry: Kinetics of the Gas Phase Reaction $\mathrm{Mu}+\mathrm{F}_{2} \rightarrow$ $\mathrm{MuF}+\mathrm{F}$ from 300 to $400 \mathrm{~K}$. Chem. Phys. Letts. 55, 163(1978).

36. GARWIN, R. L., LEDERMAN, L. M., WEINRICH, M.: Observations of the Failure of Conservation of Parity and Charge Conjugation in Meson Decays: the Magnetic Moment of the Free Muon. Phys. Rev. 105, 1415 (1957).

37. FRIEDMAN, J. I., TELEGDI, V. L.: Nuclear Emulsion Evidence for Parity Nonconservation in the Decay $\pi^{+} \rightarrow \mu^{+} \rightarrow \mathrm{e}^{+}$. Phys. Rev. 106, 1290 (1957).

38. SWANSON, R. A.: Depolarization of Positive Muons in Condensed Matter. Phys. Rev, 112, 580 (1958).

39. FIRSOV, V. G., BYAKOV, V. M.: Chemical Reactions Involving Muonium. A Method for Determining the Absolute Rate Constants and other Reaction Parameters. Zh. Eksp. Teor. Fiz. 47, 1074 (1964) [English trans. Sov. Phys. JETP 20, $719(1965)]$. 
40. BABAEV, A. I., BALATS, M. YA. MYASISHCHEVA, G. G. OBUKHOV, YU. V., ROGANOV, V. S., FIRSOV, V. G.: An Experimental Investigation of Chemical Reactions Involving Muonium. Zh. Eksp. Teor. Fiz. 50, 877 (1966) [English trans. Sov. Phys. JETP 23, 583 (1966)].

41. MINAICHEV, E. V., MYASISHCHEVA, G. G., OBUKHOV, YU. V., ROGANOV, V. S., SAVEL'EV, G. I., SMILGA, V. P. FIRSOV, V. G.: The Effects of Electroly tes on the Depolarization of Positive Muons. Zh. Eksp. Teor. Fiz. 66, 1926 (1974) [English trans. Sov. Phys. JETP 39, 946 (1974)].

42. FIRSOV, V. G., GOLDANSKII, V. I.: Muonium. In: Radiochemistry (A. G. MADDOCK, ed.) MTP Internat. Rev. Science, Inorg. Chem. Series Two, Vol. 8, Butterworths, London 1975, p. 1

43. BREWER, J. H., CROWE, K. M., JOHNSON, R. F., SCHENCK A., WILlIAMS, R. W.: "Fast" Depolarization of Positive Muon in Solution - the Chemistry of Atomic Muonium. Phys. Rev. Letts. 27, 297 (1971).

44. BREWER, J. H., CROWE, K. M., GYGAX, F. N., JOHNSON, R. F., FLEMING, D. G., SCHENCK, A.: Muonium Chemistry in Liquids: Evidence for Transient Radicals. Phys. Rev. A 9, 495 (1974).

45. BREWER, J. H., CROWE, K. M., GYGAX, F. N., SCHENCK, A.: Positive Muons and Muonium in Matter. In: Muon Physics Vol. 3. Chemistry and Solids (V. W. HuGHES, C. S. WU, eds.) Academic Press, New York 1975, p. 3.

46. Percival, P. W., Roduner, E., Fischer, H., CAMANi, M., GYGAX, F. N., SCHENCK, A.: Bimolecular Rate Constants for Reactions of Muonium in Aqueous Solutions. Chem. Phys. Letts. 47, 11 (1977).

47. Roduner, E., Percival, P. W., FISCher, H., CAMANI, M., GYGAX, F. N., SCHENCK, A.: Rate Constants for Reactions of Muonium in Aqueous Solutions. In: Mesons in Matter Proc. Int. Symp. on Meson Chemistry and Mesomolecular Processes in Matter, Dubna, June 1977, p. 326.

48. JEAN, Y. C., BREWER, J. H., FLEMING, D. G., GARNER, D. M., MIKULA, R. J., VAZ, L. C., WALKER, D. C.: Reactivity of Muonium Atoms in Aqueous Solution. Chem. Phys. Letts. 57, 293 (1978).

49. RODUner, E., PERCIVAL, P. W., Fleming, D. G., HOCHMANN, J., FISCHER, H.: Muonium-Substituted Transient Radicals Observed by Muon Spin Rotation. Chem. Phys. Letts 57, 37 (1978).

50. NICHOLAS, J.: Chemical Kinetics. A Modern Survey of Gas Reactions, Harper \& Row, London 1976.

51. Connor, J. N. L., JakUbetZ, W., MANZ, J.: Muonium Chemistry: Quantum Mechanical Calculations for the Collinear Reaction $\mathrm{Mu}+\mathrm{F}_{2}(v=0) \rightarrow \mathrm{MuF}\left(v^{\prime} \leqslant 3\right)+\mathrm{F}$. Chem. Phys. Letts. 45, 265 (1977)

52. CONNOR, J. N. L., JAKuBETZ, W., MANZ, J.: Isotope Effects in the Reaction $X+F, \rightarrow X F+F(X=M u, H, D, T)$ : A Quantum Mechanical and Information Theoretic Investigation. Chem. Phys. 28, 219 (1978).

53. ANBAR, M., ROSS, F., Ross, A. B.: Selected Specific Rates of Reactions of Transients from Water in Aqueous Solution. II. Hydrogen Atom, Nat. Stand. Ref. Data Ser., Nat. Bur. Stand. (U. S.) 51, U. S. Government, Washington 1975.

54. ElDRUP, M., SHANTAROVICH, V. P., MOGENSEN, O. E.: Inhibition of Ps Formation by Strong Ps Quenchers. Chem. Phys. 11, 129 (1975).

55. RODUNER, E., FISCHER, H.: The Importance of Tunnelling in Chemical Reactions of Muonium. In: Proc. 1st. Int. Topical Meeting on Muon Spin Rotation, Rorschach, Sept. 1978, Hyperfine Interactions, in press.

56. RODUNER, E.: private communication.

57. HARMONY, M. D.: Quantum Mechanical Tunnelling in Che mistry. Chem. Soc. Rev. 1, 211 (1972).

58. Fischer, H., Hellwege, K.-H. (eds.): Magnetic Properties of Free Radicals. Part b. Organic C-Centred Radicals, LandoltBörnstein, New Series, Group II, Vol. 9, Springer-Verlag, Berlin 1977.

59. FESSENDEN, R. W.: ESR Studies of Internal Rotation in Radicals. J. Chim. Physique 61, 1570 (1964).

60. LLOYD, R. V., WOOD, D. E.: Free Radicals in an Adamantane Matrix. XI. Electron Paramagnetic Resonance Study of Conformations in the $\beta$-Halo-tert-butyl Radicals. J. Am. Chem. Soc. 97,5986 (1975).
61. YIM, M. B., WOOD, D. E.: Free Radicals in an Adamantane Matrix. X. Electron Paramagnetic Resonance and INDO Study of Fluorinated Cyclohexadienyl Radicals. J. Am. Chem. Soc. 97, 1004 (1975).

62. Percival, P. W., RodUner, E., Fischer, H.: Radiolysis Effects in Muonium Chemistry. Chem. Phys. 32, 353 (1978).

63. SCHENCK, A., WILLIAMS, D. L., BREWER, J. H., CROWE, K. M., JOHNSON, R. F.: Decay of the Coherent Spin Precession of Polarized Positive Muons in Paramagnetic $\mathrm{MnCl}_{2}$ Solutions. Chem. Phys. Letts. 12, 544 (1972).

64. MINAICHEV, E. V., MYASISHCHEVA, G. G., OBUKHOV, YU. V., ROGANOV, V. S., SAVE L'EV, G. I., FIRSOV, V. G. "Slow" Depolarization of Positive Muons in Aqueous Solutions of Paramagnetic Ions. Zh. Eksp. Teor. Fiz. Pis. Red. 19, 149 (1974) [English trans. Sov. Phys. JETP Letts. 19, 92 (1974)].

65. JEAN, Y. C, BREWER, J. H., FLEMING, D. G., WALKER, D. C.: Spin-Conversion of Muonium by Interaction with Paramagnetic Ions. To be published.

66. POOLE, C. P., FARACH, H. A.: Relaxation in Magnetic Resonance, Academic Press, New York 1971.

67. TAWARA, H., R USSEK, A.: Charge Changing Processes in Hydrogen Beams. Rev. Mod. Phys. 45, 178 (1973).

68. MOZUMDER, A.: Charged Particle Tracks and their Structure. In: Advances in Radiation Chemistry (M. BURTON, J. L. MAGEE, eds.), Wiley-Interscience, New York 1969, Vol. 1, p. 1

69. Percival, P. W.: Participation of the OH Radical in the Terminal Muon Spur. In: Proc. Ist. Int. Topical Meeting on Muon Spin Rotation, Rorschach, Sept. 1978, Hyperfine Interactions, in press.

70. DRAGANIC, I. V., DRAGANIC, Z. D.: The Radiation Chemis try of Water, Academic Press, New York 1971.

71. LAM, K. Y., HUNT, J. W.: Picosecond Pulse Radiolysis-VI. Fast Electron Reactions in Concentrated Solutions of Scavengers in Water and Alcohols. Int. J. Radiat. Phys. Chem. 7, 317 (1975).

72. MOGENSEN, O. E.: Spur Reaction Model of Positronium Formation. J. Chem. Phys. 60, 998 (1974).

73. TAO, S. J.: The Formation of Positronium in Molecular Substances. Appl. Phys. 10,67 (1976).

74. DUPLATre, G., ABBE, J. CH., MADDOCK, A. G., HAESSLER, A.: Inhibition and Enhancement of Positronium Formation in Aqueous Solutions of Halides, Sulfide and Thiocyanate. Radiat. Phys. Chem. 11, 199 (1978).

75. MuUS, L. T., ATKINS, P. W., MCLAUChLAN, K. A. PETERson, J. B. (eds.): Chemically Induced Magnetic Polarization, Reidel, Dordrecht 1977.

76. BUXTON, G. V., GILlIS, H. A., KLASSEN, N. V.: Two Types of Localized Excess Electrons in Crystalline $\mathrm{D}_{2} \mathrm{O}$ Ice. Can. J. Chem. 55, 2385 (1977).

77. Chase, W. J., HUNT, J. W.: Solvation Time of the Electron in Polar Liquids. Water and Alcohols. J. Phys. Chem. 79, 2835 (1975).

78. GILLES, L., BONO, M. R., SCHMIDT, M.: Electron in Cold Alcohols: A Pulse Radiolysis Study in Ethanol. Can. J. Chem. $55,2003(1977)$

79. BYAKOV, V. M., GRAFUTIN, V. I., KOLDAEVA, O. V. MINAICHEV, E. V., NICHIPOROV, F. G., OBUKHOV, YU. V., STEPANOVA, O. P.: Investigation of Nonsolvated Electron Reactions by Means of the Positron Annihilation Method. Chem. Phys. 24, 91 (1977).

80. HUNT, J. W., CHASE, W. J.: Temperature and Solvent Dependence of Electron Scavenging Efficiency in Polar Liquids: Water and Alcohols. Can. J. Chem. 55, 2080 (1977).

81. TACHIKAWA, E., ARATONO, Y.: The Reactions of Recoil Tritium Atoms with Water. Energetic and Thermal Reaction Yields. J. Inorg. Nucl. Chem. 38, 193 (1976).

82. ARATONO, Y., TACHIKAWA, E.: The Reactions of Recoil Tritium Atoms with Water. III. Apparent Phase Effect Between Liquid and Solid Phases. J. Inorg. Nucl. Chem. 39, 555 (1977).

83. MALCOLME-LAWES, D. J.: Reactions of Energetic Hydrogen Atoms with Bromine and Hydrogen Bromide. J. Chem. Soc. Faraday II 74, 182 (1978).

84. MOGENSEN, O. E.: Track Effects and Muonium Formation. In: Proc. Ist. Int. Topical Meeting on Muon Spin Rotation, Rorschach, Sept. 1978, Hyperfine Interactions, in press. 